\title{
Mechanisms of silicide formation by reactive diffusion in thin films
}

\author{
Dominique Mangelinck ${ }^{1,}$ * \\ ${ }^{1}$ IM2NP, Aix Marseille Université, CNRS, Case 142, 13397 Marseille Cedex 20, France \\ adominique.mangelinck@im2np.fr \\ * corresponding author
}

Keywords: Silicide; reactive diffusion; nucleation; lateral growth; Ni alloys; diffusion barrier.

\begin{abstract}
Silicide formation by reactive diffusion is of interest in numerous applications especially for contact formation and interconnections in microelectronics. Several reviews have been published on this topic and the aim of this chapter is to provide an update of these reviews by focusing on new experiment results. This chapter presents thus some progress in the understanding of the main mechanisms (diffusion/reaction, nucleation, lateral growth...) for thin and very thin films (i.e. comprised between 4 and $50 \mathrm{~nm}$ ). Recent experimental results on the mechanisms of formation of silicide are presented and compared to models and/or simulation in order to extract physical parameters that are relevant to reactive diffusion. These mechanisms include nucleation, lateral growth, diffusion/interface controlled growth, and the role of a diffusion barrier. The combination of several techniques including in situ techniques (XRD, XRR, XPS, DSC) and high resolution techniques (APT and TEM) is shown to be essential in order to gain understanding in the solid state reaction in thin films and to better control these reaction for making contacts in microelectronics devices or for other application.
\end{abstract}

\section{Introduction}

Reactive diffusion and thin film reaction are of interest in numerous applications such as protective coatings in metallurgy, intermetallic control in aeronautics, interlayer in diffusion welding, and contact formation and interconnections in microelectronics.

The use of metallic silicides as contact materials in MOS structure since more 40 years has significantly contributed to the development of microelectronics [1,2]. Indeed one of the challenges of nanoelectronics is to create a contact on the active zones of transistors or memories. This contact has to be reliable and fully compatible with both the fabrication processes and the other materials constituting the transistor. The metallic silicides obtained by reaction between a metal and silicon (salicide process) can fill these constraints. $\mathrm{CoSi}_{2}$ and $\mathrm{TiSi}_{2}$ were first used as contacts in submicrometric devices but the nickel mono-silicide phase ( $\mathrm{NiSi}$ ) has replaced them in advanced technologies, i.e. since $65 \mathrm{~nm}$. Indeed NiSi has many advantages: it consumes less silicon, has a low resistivity $(\sim 14 \mu \Omega-\mathrm{cm})$, independent of linewidth and forms at low temperatures below $400^{\circ} \mathrm{C}$ [3]. However, a major drawback is that the high resistivity $\mathrm{NiSi}_{2}$ phase forms at the expense of $\mathrm{NiSi}$ around $750-800^{\circ} \mathrm{C}$. The use of alloy element has been found to alleviate this major concern. The addition of a few \% of Pt (typically 5 to 10\%) to a $\mathrm{Ni}$ film has been shown to stabilize the low resistivity $\mathrm{NiSi}$ phase through an increase by approximately $150{ }^{\circ} \mathrm{C}$ of the temperature of $\mathrm{NiSi}_{2}$ formation [4]. This was associated with a better resistance to morphological degradation and has allowed a better integration of NiSi as contacts for nanometric transistors [5]. The Salicide process using a $\mathrm{Ni}(\mathrm{Pt})$ alloy has thus been introduced in sub-90 nanometers CMOS technologies to improve the NiSi process integration. A higher Pt concentration (10 at.\%) is now in volume production for CMOS application below $28 \mathrm{~nm}$. However controlling contacts in such low dimensions requires a good understanding of reaction at the nanoscale.

These silicide are fabricated by reactive diffusion between a metal or a metallic alloy thin film and the Si substrate [6] and there has been many studies performed to understand these reactions. Several reviews have been published on the formation [6-8], stress [9] and properties [10] of these silicide 
films with thickness in the range of a few hundreds of nms. The reactions in thin films (typically above $50 \mathrm{~nm}$ ) [6] are usually characterized by a sequential growth, the absence of some equilibrium phases, and sometimes the growth of metastable phases, while the simultaneous parabolic growth of all the equilibrium phases is usually observed in bulk interdiffusion couples. However, the fundamental mechanisms of the silicide formation are still not fully understood, especially for small film thicknesses $(<50 \mathrm{~nm})$ where the growth may be mainly controlled by the interfacial reaction. Furthermore, other phenomena like nucleation [11], lateral growth [12], stress [13-15], texture [16], and transient phase formation with very short lifetime [3,17] are playing an important role for actual devices in which the silicide thickness is about $10 \mathrm{~nm}$. Recent results for ultra-thin nickel silicide films [18-20] show that entirely new phase formation sequences can be observed when the nickel film thickness drops below a critical thickness of $4 \mathrm{~nm}$. The increasing importance of interface energy due to the reduction of the layer thicknesses results in a strong texture of the phases that form. Even thermodynamically unstable phases can form due to epitaxial stabilization, as evidenced for $\theta-\mathrm{Ni} 2 \mathrm{Si}$ [18-20]. One of the major issues with very thin silicide films concern a severely deteriorated morphological stability because of capillary effects. Indeed, thin films of NiSi often suffer from poor morphological stability and start to agglomerate at $500^{\circ} \mathrm{C}$. Since the agglomeration of thin films is driven by a minimization of interface energy, it is expected that thinner films will agglomerate faster, i.e., have a lower agglomeration temperature. However this holds true only if the as-deposited Ni film thickness remains larger than $5 \mathrm{~nm}$, while for thinner layers the resulting nickel-silicide layer is much more resistant to agglomeration and exhibits an extraordinary morphological stability up to $800^{\circ} \mathrm{C}$ [18-20]. This was attributed to the formation of an epitaxial nickel-silicide layer.

This chapter doesn't aim to be an extensive review of the work on silicides. Its goal is to provide some basis to understand the mechanisms of formation of these intermetallic compounds. It will be mainly focused on the $\mathrm{Ni}$ and $\mathrm{Ni}$ alloy silicides since they are used in microelectronics today and have been thus largely studied. The goal is not to investigate ultra thin films (i.e. $<4 \mathrm{~nm}$ ) but to present progress in the understanding of the main mechanisms (diffusion/reaction, nucleation, lateral growth...) for thin and very thin films (i.e. comprised between 4 and $50 \mathrm{~nm}$ ).

\section{Growth of silicides: general behaviour}

The growth of silicide has been the subject of a large number of studies that were summarized in several reviews [6,8]. It is characterized by two dominant features: a) most of the measurements of diffusion were made during reactive diffusion, namely during the formation of a silicide by reaction of a metal, or another silicide with $\mathrm{Si}$, and b) most of this work concerns thin films. Indeed the abundant literature on the growth of silicide mainly deals with a few hundreds of nms thin films $[6,8]$. In addition to the interest for application, this facilitates measurements because in films up to about $500 \mathrm{~nm}$ thick and at the temperatures and scales at which growth is observed to occur, phases generally form sequentially, which greatly simplifies the interpretation of growth kinetics. While the silicide formation has been mainly studied in thin films because of the applications in microelectronics, there are comparatively less work done on bulk diffusion couple [21].

However bulk diffusion couple are very instructive for the understanding of silicide formation since all the phases stable at the annealing temperature are present as layers of uniform thickness. Indeed for the relatively high temperature and time used for diffusion couple, the interface are expected to be at equilibrium and diffusion couple can be used to determine the phase diagram. Under this conditions, the square of these thicknesses varies linearly with time as expected for a growth controlled by diffusion. It can be shown that the growth rate of a given silicide in a diffusion couple depends of the interdiffusion coefficient in this silicide but also of the interdiffusion coefficients in the other silicides that are growing concurrently [22,23]. From the growing rate of the silicides, one can thus determine the interdiffusion coefficients in the silicides. 
For thin film experiments, a metal film is deposited on a silicon substrate and the silicide thickness is measured after various heat treatments. Rutherford backscattering spectrometry (RBS) is very efficient for this purpose [24] since it can measure the change in the metal (and Si) profile(s) for thicknesses between $10 \mathrm{~nm}$ and $1 \mu \mathrm{m}$. From the measurement of the thickness as a function of time, one obtains the growth rate for a given temperature and by plotting an Arrhenius diagram of the growth rate, an activation energy for the growth can be determined. More recently in situ measurement during the heat treatment have also been used to measure the kinetics of silicide and germanide formation. This methods relies on measuring a physical parameter that changes during the phase formation such, e. g. the resistance, the heat release, the amount of diffracting materials and the thickness for measurement by sheet resistance [25], differential scanning calorimetry [12,26], X ray diffraction $[3,27]$ and $X$ ray reflectivity [28] respectively. Isothermal or constant heating rate can be used, the later allowing to obtain the activation energy $[21,29,30]$. These mode of experimentation is much less time consuming than the previous ones and allow a more precise analysis of the sequence and kinetics even for phases with complex behavior as will be exemplified latter in this chapter.

Most of the time, when plotted properly as $\mathrm{L}^{2}$ vs. $\mathrm{t}$ (with $\mathrm{L}$ being the thickness of the growing layer and $\mathrm{t}$ the time), the slope gives the growth constant $\mathrm{k}$ and measurements at different temperatures yield the activation energy. For isotherm heat treatments, the growth rate $\mathrm{k}$ is usually constant indicating that most of the kinetics of the metal/silicon reactions are controlled by diffusion processes as in bulk diffusion couple. However the relationship between the growth rate and the diffusion coefficients is not straightforward. Since growth occurs quite often at low temperatures with respect to the melting points of the different phases, grain boundary (GB) diffusion play a role. There are thus potentially two mobile elements and two sets of paths (lattice and grain boundaries), hence one may ultimately have to separate four different diffusion coefficients and four activation energies. Moreover lattice diffusion in intermetallics [31,32] depends on the structure and can be influenced by changes in composition. In fact for each intermetallic one should take into account the possibility of having structural defects (structural vacancies or antisite) and the disorder associated with diffusion [32]. A general trend of diffusion studies in intermetallics is that most of the compounds studied admit large departure from stoichiometry.

Luckily the silicides are generally stoichiometric (line compounds) that results in less complex diffusion behaviour. Moreover, in silicide (and in intermetallic), quite often only one atomic species are mobile under the experimental growth conditions (all the more true as the temperature is low, as is usually the case for thin film reactions). Indeed, in marker experiments used to determine the moving species during silicide formation [6], it is generally found that metal atoms constitute the dominant mobile species in metal-rich silicides, and $\mathrm{Si}$ atoms in silicon-rich ones. This observation has been generalized as the "Ordered $\mathrm{Cu}_{3} \mathrm{Au}$ Rule" [6] according to which generally in $\mathrm{A}_{\mathrm{m}} \mathrm{B}_{\mathrm{n}}$ compounds with $\mathrm{m} / \mathrm{n}$ equal to or greater than 2 , the majority atoms (A) are much more mobile than the atoms of the minority species (B). This is related to the structures where the A atoms can migrate on a continuous network of $A$ lattice sites, whereas the migration of the $B$ atoms requires that these occupy A sites with an increase in activation energy for diffusion that should be commensurate with the heat of ordering (or of compound formation, per B atom). Diffusion will thus be favored if the structure of the compound is such that one of the elements may diffuse on its own sub-lattice: this is more likely for the majority element that can diffuse on its own sub-lattice by near neighbor jumps while the minority element has to go through a "high energy" position (anti-site).

One has also to be careful when analyzing the results of silicide formation. Because many silicides exist only within very narrow limits of composition, growth results cannot be properly interpreted in terms of Fick's law. It is more appropriated to consider diffusion in terms of a modified NernstEinstein equation: 


$$
J_{A}=c_{A}\left(\frac{D_{A}}{k_{B} T}\right) \frac{\partial \mu_{A}}{\partial z} .
$$

where the flux of A atoms, $\mathrm{J}_{\mathrm{A}}$, is expressed as the product of the concentration of $\mathrm{A}$ atoms, $\mathrm{c}_{\mathrm{A}}$, their mobility $\left(\mathrm{D}_{\mathrm{A}} / \mathrm{kT}\right)$ and $\mathrm{d} \mu_{\mathrm{A}} / \mathrm{dz}$, the gradient of chemical potential (i.e. the force on these atoms). Ideally, $\mathrm{D}_{\mathrm{A}}$ here is equal to $\mathrm{D}_{\mathrm{A}}{ }^{*}$, the tracer diffusion coefficient in the formed compound. For the sake of simplicity, $d \mu_{A} / d z$, the gradient of chemical potential is taken equal to $\Delta \mathrm{G}_{\mathrm{A}} / \mathrm{L}$ with $\Delta \mathrm{G}_{\mathrm{A}}$ the free energy change per moving A atom (from the free energy of formation of the compound, at least in elemental A-B reactions):

$$
J_{A}=c_{A}\left(\frac{D_{A}}{k_{B} T}\right) \frac{\Delta G_{A}}{L} .
$$

For a phase growing alone from the reaction between A and B elements, one obtains:

$$
L^{2}=k_{D} t
$$

With the following expression for the growth rate, $\mathrm{k}_{\mathrm{D}}$, if growth occurs by the motion of $\mathrm{A}$ atoms only (this is usually the case as explained before):

$$
k_{D}=2\left(\frac{\Delta G_{F}}{k_{B} T}\right)\left(\frac{D_{A}^{0}}{p}\right) \exp \left(\frac{-Q}{k_{B} T}\right) .
$$

Here, $\Delta G_{F}$ for solid state reactions can be taken as the heat of formation of the compound $A_{p} B_{q}$ per mole, and $Q$ the activation energy for the diffusion of $A$ atoms in $A_{p} B_{q}$.

Gas and d'Heurle [6,21,33,34] have performed a compilation of the different results for diffusion controlled growth of silicides. They pointed out that an important difference between thin film and bulk diffusion couple is the relatively high rates of formation and quite low activation energies for diffusion controlled growth of thin films. Many reasons may explain this increase in diffusion rates during solid state reaction: (i) the influence of the driving force which in reactive diffusion is the formation of the new phase (ii) the fact that the growing layer is in contact with pure metal and $\mathrm{Si}$ and may thus grow with compositions limits in excess of the equilibrium ones. Such a departure from stoichiometry may correspond to structural defects (anti sites or vacancies) which may enhance diffusion, (iii) the creation of point defects associated to the formation of the phase at the interfaces, and (iv) the role of extended defects (e.g., silicide grain boundaries) which may increase the mass transport through the silicide layer. In order to get a better understanding of diffusion processes during silicide formation, it is thus important to determine the influence of these different factors.

The similarity between the relations between the rate of formation, the activation energy $(Q)$ and the melting temperature $(\mathrm{Tm})$ for silicide formation in thin film and for grain boundary in metals is in accordance with a strong contribution of grains boundary diffusion linked to the thin film microstructure [6,21,33,34]. This was further evidenced by the work of Barge et al. [22,23]. They evaluate the different factors affecting diffusion during silicide formation by comparing the kinetics of growth of thin films and bulk diffusion couples with the diffusion parameters (lattice and GB diffusion coefficients) measured by classical diffusion methods. In order to compare these diffusion coefficients to those deduced from the growth of $\mathrm{CoSi}_{2}$ (DNE), the motion of both Co and $\mathrm{Si}$ and the contribution of lattice and GB diffusion have thus to be taken into account. The last contribution is approximated by the use of an effective diffusion coefficient: 


$$
D_{e f f}=D_{L}+\frac{\delta}{2 d} D_{G B} \rightarrow \quad D_{e f f}=\left(2 D_{L}^{C o}+D_{L}^{S i}\right)+\frac{\delta}{2 d}\left(2 D_{G B}^{C o}+D_{G B}^{S i}\right)
$$

This coefficient is plotted as a function of the grain size in Fig. 1 and is compared to the diffusion coefficient deduced from the Nernst-Einstein equation for diffusion couple and thin film. A very reasonable agreement is obtained between the two sets of coefficients provided that a grain size of $10 \mu \mathrm{m}$ is assumed for bulk couples and $0.01 \mu \mathrm{m}$ for thin films which correspond to the actual experimental values. This agreement between the two sets of data implies that the effective diffusion coefficients during growth are not enhanced by the creation of point defects which have been shown to occur under some circumstances $[35,36]$. This might be due to the absence of defect creation or to the dominance of grain boundary diffusion which may be insensitive to such defect creation.

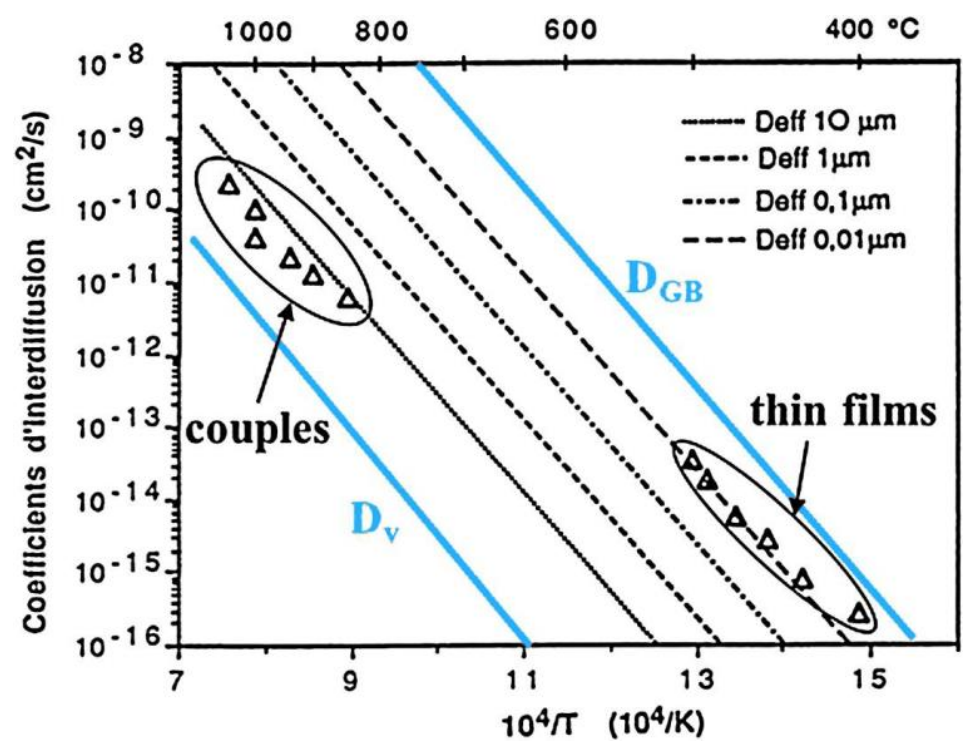

Fig. 1: Comparison between the efficient diffusion coefficient $\left(\mathrm{D}_{\text {eff }}\right)$ (deduced from self-diffusion measurement by taking into account the mobility of both elements and the grain size) and the Nernst-Einstein diffusion coefficient (DN.E.) deduced from reactive diffusion experiments. Different grain sizes (ranging from 10 to $0.1 \mu \mathrm{m})$ are used to calculate $\mathrm{D}_{\text {eff }}$. From Ref. $[22,23]$.

Apart from the contribution of grain boundaries in the kinetics of formation of silicide that was described now, there exist other differences in behavior between thin films and their equivalent bulk couples, such as the absence of certain phases or the general observation of sequential formation in thin films instead of the simultaneous formation often reported for bulk couples [6,8,11]. Some experimental insights of the mechanisms behind these difference will be now described based on the $\mathrm{Ni}$ silicides thin film formation.

\section{Mechanisms of formation}

Ni silicides formation in thin films. As pointed out before, there are differences between the growth of silicide in thin film and in bulk diffusion couples. In order to illustrate these difference and the recent progress in the field, we will now present results on the formation of the $\mathrm{Ni}$ silicides since this system $(\mathrm{Ni} / \mathrm{Si})$ have been the most studied and constitutes a typical example of thin film reactions. Numerous studies were carried on Ni thin film reaction with silicon in order to clarify the silicide formation mechanisms both for its interest for application and as a characteristic system for reactive diffusion [37,38]. Most of the studies on the reaction between a pure Ni thin film and the Si substrate have shown that the following sequence of phases occurs during the reaction (Fig. 2): $\delta-\mathrm{Ni}_{2} \mathrm{Si}$ appears as the first phase and grow at low temperature (from $250^{\circ} \mathrm{C}$ ) until the full consumption of the Ni metal film. The NiSi phase grows then at the expense of the $\delta-\mathrm{Ni}_{2} \mathrm{Si}$ phase and is stable in a temperature range up to $700-800^{\circ} \mathrm{C}$. The third phase $\mathrm{NiSi}_{2}$ grows usually after $\mathrm{NiSi}$ at a temperature higher than $700^{\circ} \mathrm{C}$ since it has a difficult nucleation $[8,11]$.

Comparing to the Ni-Si phase diagram [39], only three phases are formed in thin film while six silicides are stable at low temperature. Several phases are thus missing and, in addition, the phases 
appears sequentially instead of the simultaneous formation observed usually in bulk diffusion couples. In addition to the three phases commonly observed in most of the experimental works $(\delta$ $\mathrm{Ni}_{2} \mathrm{Si}, \mathrm{NiSi}$ and $\mathrm{NiSi}_{2}$ ), it was shown that during the deposition of $\mathrm{Ni}$ film on a Si substrate, a amorphous $\mathrm{Ni}-\mathrm{Si}$ intermixed layer is usually formed at the interface between the Ni film and the $\mathrm{Si}$ substrate [40,41]. Moreover, other studies performed on Ni thin films between 10 and $100 \mathrm{~nm}$ using in-situ X-Ray diffraction (XRD) have shown the formation of a transient phase $[14,42,43]$. This transient phase was first identified as $\mathrm{Ni}_{3} \mathrm{Si}_{2}$ [3] but a deeper analysis based on poles figures leads to the identification of $\theta-\mathrm{Ni}_{2} \mathrm{Si}$ [44]. In the Ni-Si phase diagram, $\theta-\mathrm{Ni}_{2} \mathrm{Si}$ is only stable around $825^{\circ} \mathrm{C}$, while in thin films, it can thus be metastable since it has been observed at lower temperature (around $\left.300^{\circ} \mathrm{C}\right)$.

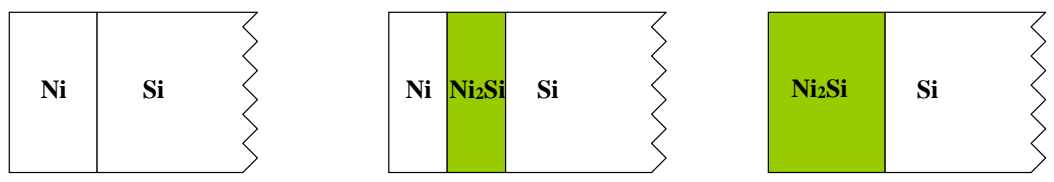

$\mathrm{T} \sim 200-300{ }^{\circ} \mathrm{C}$ : formation of $\mathrm{Ni}_{2} \mathrm{Si}$ : DIFFUSION controlled, $\mathrm{Ni}$ diffusion
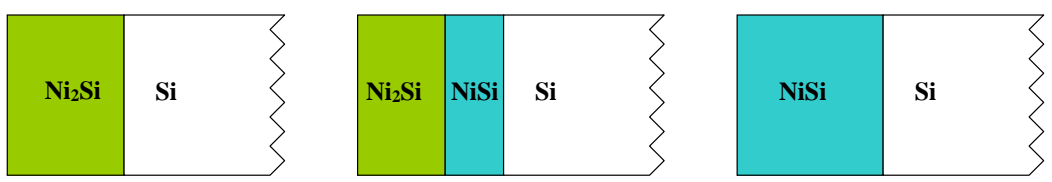

T 250-350 ${ }^{\circ} \mathrm{C}$ : formation of NiSi : DIFFUSION controlled , Ni diffusion

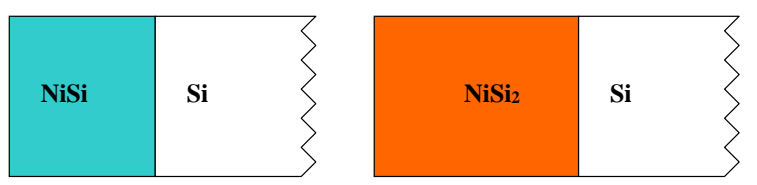

$\mathrm{T} \sim 750-800^{\circ} \mathrm{C}:$ formation of $\mathrm{NiSi}_{2}:$ NUCLEATION controlled , Ni diffusion
Fig. 2: Schematic of the Ni silicide formation in thin film showing the sequential growth of silicides at low temperature and the nucleation of $\mathrm{NiSi}_{2}$ at high temperature.

The reaction between $\mathrm{Ni}$ thin films and Si substrate are thus characterized by the following points: lack of some stable phases, growth of metastable phase, sequential formation. These points are representative not only to the $\mathrm{Ni} / \mathrm{Si}$ system but more generally to the phase formation in thin film. In the following, we will bring some explanations for these behaviors even if the mechanisms involved in the Ni silicide formation are still not fully understood. Among these mechanism, nucleation, lateral growth, reaction at interface, are of great importance especially in the case of nanometric film. Some experimental examples will now be given in order to better understand these mechanisms and/or to show how additive element can be used to modify or control them.

Nucleation. Nucleation plays a crucial role in the silicide formation. Not only it is the first step involved in the silicide formation but it can also control (or limit) the formation of a silicide. This is the case of $\mathrm{NiSi}_{2}$ that only appears at temperatures higher than $700^{\circ} \mathrm{C}$ during the reaction of $\mathrm{Ni}$ thin film and Si substrate (Fig. 2). Even if this temperature is much higher than the ones for the other silicides $\left(\delta-\mathrm{Ni}_{2} \mathrm{Si}\right.$ and $\left.\mathrm{NiSi}\right)$, it was of concern for the use of $\mathrm{NiSi}$ as contact materials. However this concern was solved by the addition of alloy element [4]. Not only alloy element addition can modify the nucleation of $\mathrm{NiSi}_{2}$ but also the nucleation of the first phase to grow and thus the phase sequence. Two examples illustrating these points will be detailed now.

Nucleation of NiSiz: addition of platinum. Mangelinck et al. [4] have studied the silicide formation for pure $\mathrm{Ni}$ and $\mathrm{Ni}(5 \% \mathrm{Pt}$ ) films deposited onto (100) $\mathrm{Si}$ and (111)Si wafers by sputter deposition using pure $\mathrm{Ni}$ and $\mathrm{Ni}(\mathrm{Pt})$ alloy targets. The formation of various silicides at different temperatures was monitored by in situ x-ray photoelectron spectroscopy (XPS) during thermal annealing. Fig. 3 shows the variation of the Ni $2 p$ XPS peak position (binding energy) with 
temperature during in situ annealing of $\mathrm{Ni}$ and $\mathrm{Ni}(\mathrm{Pt})$ films. As XPS is surface sensitive, a change in the Ni peak position is observed when the silicide front reaches the surface. The temperature at which this occurs is dependent on the film thickness and on the heating rate. There are clearly four plateaus for the pure $\mathrm{Ni}$ film which correspond to $\mathrm{Ni}, \delta-\mathrm{Ni}_{2} \mathrm{Si}, \mathrm{NiSi}$, and $\mathrm{NiSi}_{2}$, respectively. The binding energy and the temperature corresponding to the onset of each of the plateaus are in accordance with previous studies on Ni silicides [45]. The formation of $\delta-\mathrm{Ni}_{2} \mathrm{Si}$ occurs around $250^{\circ} \mathrm{C}$, and $\mathrm{NiSi}$ starts to form when the entire $\mathrm{Ni}$ film has been transformed into $\delta-\mathrm{Ni}_{2} \mathrm{Si}$ [46]. The major difference in the two curves in Fig. 3 is the length of the NiSi plateau which shows that NiSi is stable at temperatures up to $900{ }^{\circ} \mathrm{C}$ in the presence of Pt. This is well above the nucleation temperature of about $750{ }^{\circ} \mathrm{C}$ for pure $\mathrm{NiSi}_{2}$

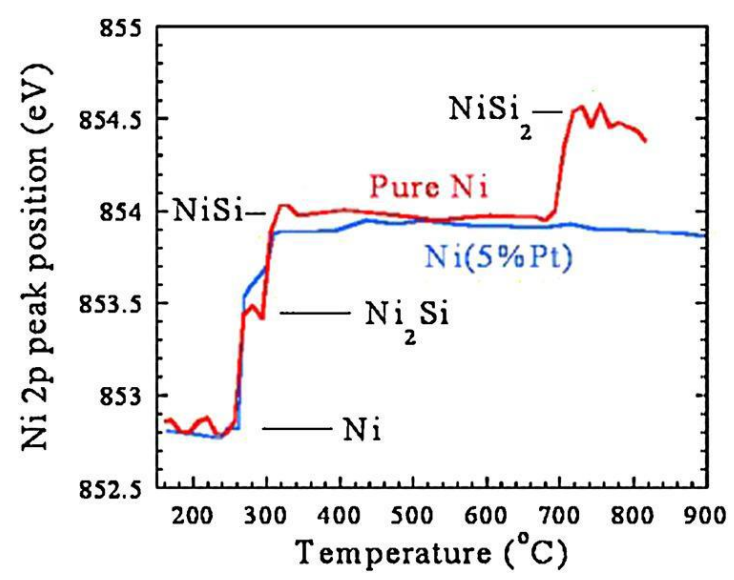

Fig. 3: Stabilization of NiSi by addition of Pt : variation of the Ni $2 p$ XPS peak position (binding energy) with the temperature during in situ annealing of $\mathrm{Ni}$ (red line) and $\mathrm{Ni}(\mathrm{Pt})$ (blue line) films on (100)Si inside a XPS system. From Ref. [4].

As the formation of $\mathrm{NiSi}_{2}$ on crystalline $\mathrm{Si}$ substrate is controlled by nucleation [11], the increase in the NiSi stability can be explained on the basis of changes in the interfacial energies and the free energy for silicide formation. Nucleation of a phase occurs when the decrease in free energy Nucleation of a phase occurs when the decrease in free energy $(\Delta \mathrm{G})$ of a reaction (here: $\mathrm{NiSi}+\mathrm{Si} \rightarrow$ $\left.\mathrm{NiSi}_{2}\right)$ just exceeds the increase in the interfacial energy $(\Delta \sigma)$ associated with the creation of the new phase $\left(\Delta \sigma=\sigma\left(\mathrm{NiSi}_{2} / \mathrm{Si}\right)+\sigma\left(\mathrm{NiSi}_{2} / \mathrm{NiSi}\right)-\sigma(\mathrm{NiSi} / \mathrm{Si})\right)$. The critical activation free energy for nucleation in such cases is proportional to a quantity $\Delta \sigma^{3} / \Delta \mathrm{G}^{2}$ :

$$
\Delta \mathrm{G}^{*}=(\Delta \sigma)^{3 /}(\Delta \mathrm{G})^{2} .
$$

The formation of $\mathrm{NiSi}_{2}$ at high temperature was attributed to a nucleation problem mainly due to a low driving force, $\Delta \mathrm{G}[11]$ even if addition of alloy elements may influence both $\Delta \sigma$ and $\Delta \mathrm{G}$ terms. The effect of alloy addition on the stability of the Ni mono- and disilicide can be examined as follows. The addition of a small amount of solute results in a decrease of the Gibbs energy and thus to a stabilization of the silicide. In addition, for a given concentration of the alloy element, the decrease in the Gibbs energy is likely to be higher for an element with high solubility than for an element with low solubility. As NiSi and PtSi have the same crystallographic structure (orthorhombic, type MnP) and a small difference in their lattice parameters (within 15\%), a pseudo binary solid solution may formed for the full range of concentration. The decrease in $\mathrm{G}(\mathrm{NiSi})$ induced by the formation of the $\mathrm{NiSi}(\mathrm{PtSi})$ solid solution is thus expected to be relatively high. On the other hand, the solubility of $\mathrm{Pt}$ in $\mathrm{NiSi}_{2}$ seems to be low and the change in $\mathrm{G}\left(\mathrm{NiSi}_{2}\right)$ is likely to be small. One can thus reasonably expect a smaller decrease in free energy for the reaction $\mathrm{NiSi}+\mathrm{Si} \rightarrow \mathrm{NiSi}_{2}$ due to the presence of Pt. Pt can also induce changes in the texture of the silicides and thus changes in $\Delta \sigma$ [47]. This finding has been largely applied to fabricate the contact in microelectronics devices.

Nucleation of the first Ni silicide: role of the intermixed layer. The nature of the first crystalline $\mathrm{Ni}$ silicide to grow was shown to be dependent on several parameters and especially on the thickness and composition of the metal film. Putero et al. have shown that, for $\mathrm{Ni}(13$ at $\% \mathrm{Pt})$ films, $\theta-\mathrm{Ni}_{2} \mathrm{Si}$ was obtained as the first phase in the phase formation sequence instead of $\delta$ - $\mathrm{Ni}_{2} \mathrm{Si}$. The same holds for 
pure $\mathrm{Ni}$ film with thickness less than $6 \mathrm{~nm}$ [20]. In the presence of 5 at.\% $\mathrm{Pt}, \delta-\mathrm{Ni}_{2} \mathrm{Si}$ still appears as the first phase and the $\theta-\mathrm{Ni}_{2} \mathrm{Si}$ phase was suppressed from the phase formation sequence. When the percentage of Pt in the Ni film was increased from 5 at.\% to 10 at.\% to improve the yield of the contacts, $\theta-\mathrm{Ni}_{2} \mathrm{Si}$ was found to replace $\delta-\mathrm{Ni}_{2} \mathrm{Si}$ as the first phase $[28,48]$. In particular, the reaction between $11 \mathrm{~nm} \mathrm{Ni}(10$ at.\% Pt) with Si substrate was found by Panciera et al. [48,49] to lead to the formation of $\theta-\mathrm{Ni}_{2} \mathrm{Si}$ as the first phase. This was evidenced by transmission electron microscopy [48] where an epitaxial relationship between $\theta-\mathrm{Ni}_{2} \mathrm{Si}$ and the $\mathrm{Si}(100)$ substrate was revealed. The formation of $\theta-\mathrm{Ni}_{2} \mathrm{Si}$ as the first phase can thus be related to the thickness of the metal layer and/or the Pt concentration in the alloy. Therefore, one may wonder what does control the formation of the first phase: the thickness of the deposited film or the concentration of Pt in this film. In a recent work, El Koussiefi et al. [50] provided some insight to this question by showing that Pt can modify the intermixed layer formed during deposition and influence the nature of the first Ni silicide to form during the reaction.
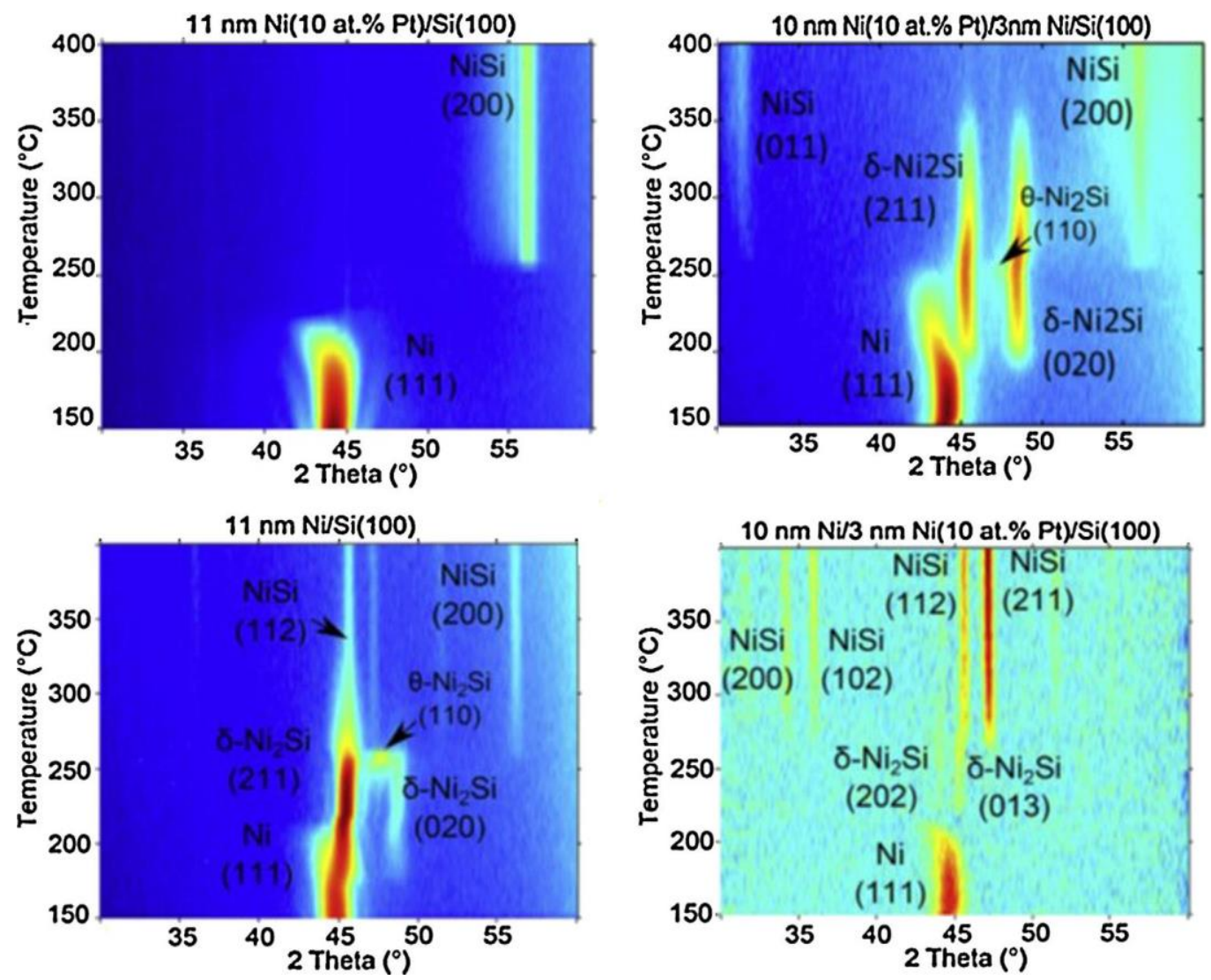

Fig. 4: Change in the first growing phase due to the insertion of a $3 \mathrm{~nm}$ layer: in situ XRD using step annealing for (a) $11 \mathrm{~nm} \mathrm{Ni}(10$ at.\% Pt)/Si(100), (b) $10 \mathrm{~nm} \mathrm{Ni(10} \mathrm{at. \%} \mathrm{Pt)/3nm} \mathrm{Ni/Si(100),} \mathrm{(b)} 11 \mathrm{~nm}$ $\mathrm{Ni} / \mathrm{Si}(100)$ and (b) $10 \mathrm{~nm} \mathrm{Ni/3nm} \mathrm{Ni(10} \mathrm{at. \%} \mathrm{Pt)/Si(100).} \mathrm{From} \mathrm{Ref.} \mathrm{[50].}$

Indeed Fig. 4 shows that a $3 \mathrm{~nm}$ thick layer inserted at the interface can change the phase sequence and especially the first phase formation. A $3 \mathrm{~nm}$ pure $\mathrm{Ni}$ inserted between the $\mathrm{Ni}(\mathrm{Pt})$ film and the $\mathrm{Si}$ substrate changed the phase sequence of the $10 \mathrm{~nm} \mathrm{Ni}\left(10\right.$ at.\% Pt) film and induced $\delta-\mathrm{Ni}_{2} \mathrm{Si}$ as the first phase: i.e. it is the same than for the $11 \mathrm{~nm}$ pure Ni reaction with Si substrate. Even more intriguing, the insertion of a $3 \mathrm{~nm} \mathrm{Ni}(10$ at.\% Pt) layer in between a pure $\mathrm{Ni}$ film and Si led to the formation of the metastable $\theta-\mathrm{Ni}_{2} \mathrm{Si}$ phase instead of the stable $\delta-\mathrm{Ni}_{2} \mathrm{Si}$ phase. To summarize, for the $\mathrm{Ni}(10$ at. $\% \mathrm{Pt}) / 3 \mathrm{~nm} \mathrm{Ni} / \mathrm{Si}$ and $\mathrm{Ni} / \mathrm{Si}$ samples, $\delta-\mathrm{Ni}_{2} \mathrm{Si}$ was the first phase to grow (Fig. 4$)$ on the contrary to the $\mathrm{Ni}(10$ at.\% $\mathrm{Pt}) / \mathrm{Si}$ and $\mathrm{Ni} / 3 \mathrm{~nm} \mathrm{Ni}\left(10\right.$ at.\%Pt) $/ \mathrm{Si}$ samples where $\theta-\mathrm{Ni}_{2} \mathrm{Si}$ is the first phase obtained (Fig. 4) 
D'Heurle and Gas [6] have argued that the first phase to grow is the fastest. However $\theta-\mathrm{Ni}_{2} \mathrm{Si}$ or $\delta-\mathrm{Ni}_{2} \mathrm{Si}$ form at the same temperature range (Fig. 4): there should thus not be a large enough difference between the growth kinetics of these two phases to change the appearance of the first phase during the formation sequence. A more suitable possibility is that the formation of the first phase is limited by the nucleation which might be depending on the composition of the intermixed layer. Indeed, it has been reported several times $[41,51]$ that, in the first steps of the reaction and/or deposition, a thin amorphous intermixed layer is formed at the metal/Si interface. This intermixed layer can grow up to a given critical thickness, for which the nucleation of the first crystalline phase starts [52]. In particular, after Ni deposition by magnetron sputtering, a $4 \mathrm{~nm}$ amorphous intermixed layer of $\mathrm{Ni}$ and $\mathrm{Si}$ was formed between the substrate and the Ni film [49]. Its composition in Si was determined to vary from 33 to 45 at.\% [49]. Furthermore, this intermixed layer has been investigated in details in the case of $11 \mathrm{~nm} \mathrm{Ni} \mathrm{(10} \mathrm{at. \%} \mathrm{Pt)} \mathrm{:} \mathrm{the} \mathrm{Si} \mathrm{gradient} \mathrm{was} \mathrm{maintained} \mathrm{and} \mathrm{an} \mathrm{incorporation} \mathrm{of} 4$ at.\% Pt was observed [49]. As the thickness of the intermixed layer is very similar in all cases, our results indicate that only the composition of the intermixed layer controls the formation of the first phase and specifically the Pt concentration in the intermixed layer. As the Si concentration in the intermixed phase varies between 33 and 45 at.\%, these concentrations correspond to the composition of $\delta-\mathrm{Ni}_{2} \mathrm{Si}$ (33 at.\%) on the metal side of the intermixed phase and to the one of the Ni rich $\theta-\mathrm{Ni}_{2} \mathrm{Si}$ on the silicon side. The formation of the intermixed layer allows thus the nucleation of $\theta-\mathrm{Ni}_{2} \mathrm{Si}$ or $\delta-\mathrm{Ni}_{2} \mathrm{Si}$ without (or with very little) change in composition. The nucleation of $\delta-\mathrm{Ni}_{2} \mathrm{Si}$ is thus expected to take place in the intermixed layer close to the metal layer and the one of $\theta-\mathrm{Ni}_{2} \mathrm{Si}$ close all over the intermixed layer as indicated in Fig. 5.

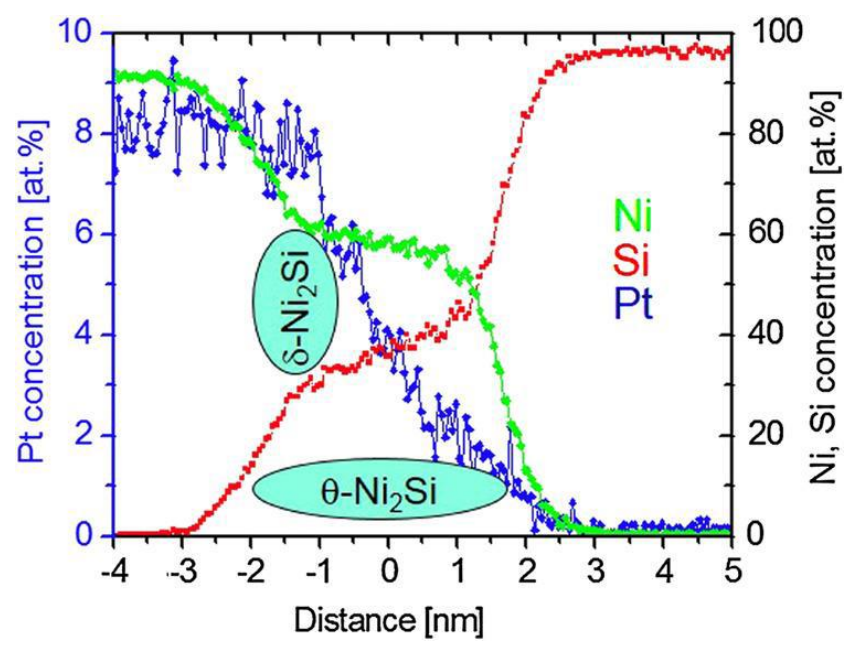

Fig. 5: Composition of the intermixed layer formed during deposition. Depth profile obtained by APT in the as deposited $11 \mathrm{~nm} \mathrm{Ni(10} \mathrm{at. \%}$ $\mathrm{Pt}) / \mathrm{Si}(100)$. The location of the nucleation of $\delta$ $\mathrm{Ni}_{2} \mathrm{Si}$ and $\theta-\mathrm{Ni}_{2} \mathrm{Si}$ is indicated. From Ref. [49].

Fig. 5 shows that the concentration of Pt in the intermixed layer is larger close to the metal where $\delta-\mathrm{Ni}_{2} \mathrm{Si}$ is expected to nucleate. From the classical nucleation theory (Eq. 6), the nucleation barrier depends on the variation of the interfaces energies $(\Delta \sigma)$ and the volume energies of the newly formed phase $(\Delta \mathrm{G})$. The presence of $\mathrm{Pt}$ may change both variation. The epitaxy of $\theta-\mathrm{Ni}_{2} \mathrm{Si}$ on $\mathrm{Si}(100)$ should favor the nucleation of $\theta-\mathrm{Ni}_{2} \mathrm{Si}$ even if this phase is metastable in the $\mathrm{Ni}-\mathrm{Si}$ phase diagram at low temperature. An additional contribution to the nucleation of $\theta-\mathrm{Ni}_{2} \mathrm{Si}$ is that the intermixed layer has the same composition gradient as $\theta-\mathrm{Ni}_{2} \mathrm{Si}$ (34 to 45 at.\%). The Pt incorporation in the phases can also change the energy for phase formation: since the solubility of $\mathrm{Pt}$ is expected to be larger in $\delta-\mathrm{Ni}_{2} \mathrm{Si}$ than in $\theta-\mathrm{Ni}_{2} \mathrm{Si}$, this should increase the driving force value of the $\theta-\mathrm{Ni}_{2} \mathrm{Si}$ formation energy and favors its formation. Although the change in energy induced by Pt incorporation is difficult to quantify, it should be substantial since it induces the growth of $\theta-\mathrm{Ni}_{2} \mathrm{Si}$ as first phase for the $\mathrm{Ni}$ (10 at.\% Pt) alloy. Therefore, when the $\mathrm{Pt}$ is incorporated in the intermixed layer, $\delta-\mathrm{Ni}_{2} \mathrm{Si}$ will have nucleation difficulties while the presence of $\mathrm{Pt}$ makes the $\theta-\mathrm{Ni}_{2} \mathrm{Si}$ phase more stable and increases its driving force $\left(G_{\theta}-G_{a}\right)$ for nucleation. Moreover, the Pt incorporation in the intermixed layer was found to be maximum close to the metal layer [49]. As this corresponds to the position where $\delta-\mathrm{Ni}_{2} \mathrm{Si}$ 
is expected to nucleate, the role of $\mathrm{Pt}$ in hindering the $\delta-\mathrm{Ni}_{2} \mathrm{Si}$ nucleation at this interface (metal layer/intermixed layer) should be enhanced since its concentration is maximum there.

In conclusion, the deposition of the $3 \mathrm{~nm}$ interfacial layer allows controlling the composition of the intermixed layer and thus the nucleation (formation) of the first phase. These findings could have a strong impact on the self-aligned silicide process used for contact production in microelectronics industry, since the modification of the intermixed layer composition allows the selection of the desired compounds.

Lateral growth. In thin film reaction, and in particular for the silicide thin film, the formation of a single product phase by solid state reaction occurs in several steps: the thickening by growth perpendicular to the interface usually controls the later stages but it has been shown that the first steps correspond to nucleation and lateral growth [12]. Examples on the role of nucleation have been presented in the former paragraph and we will now discuss the lateral growth. First evidences for lateral growth were obtained by differential scanning calorimetry (DSC) [12,27,53-57] where two peaks were found for the formation of a single product phase revealing a two steps growth for silicides [12,27,53,54] and other compounds [55-57]: (i) nucleation/lateral growth and (ii) thickening. A few other experimental evidence for lateral growth were also found. Using transmission electron microscopy (TEM) and in situ X-ray diffraction (XRD) experiments with high-intensity synchrotron radiation, Lucadamo et al. [56] evidenced a two-stage reaction mechanism in Nb/Al multilayer thinfilms. Delattre et al. found $\mathrm{CoSi}_{2}$ precipitates at the CoSi/Si interface by TEM [58] . Precipitates of $\mathrm{Al}_{9} \mathrm{Co}_{2}$ that quickly grow to form a dense layer were observed by atom probe tomography (APT) as the first product of the $\mathrm{Al} / \mathrm{Co}$ reaction [59]. A $\delta-\mathrm{Ni}_{2} \mathrm{Si}$ precipitate attributed to lateral growth was found by APT after deposition of a $\mathrm{Ni}$ film on a Si substrate [60]. In most cases, the precipitates height was found to be limited (in the order of $10 \mathrm{~nm}$ ) and several models for lateral growth were developed to reproduce these results and to determine the shape of the precipitates $[12,59,61-63]$. In the following, experimental results on the Ni silicide reaction will be compared to simulation in order to determine the kinetics and thermodynamics of lateral growth.

Lateral growth: global kinetics by DSC. In contrast to former experiments performed on selfsupported metal/Si multilayers [12,55-57], Nemouchi et al. [27] have developed a procedure to measure by DSC the reaction of thin film on a substrate. This was used to clarify the different steps of the first $\mathrm{Ni}$ silicide $\left(\delta-\mathrm{Ni}_{2} \mathrm{Si}\right)$. Fig. 6 shows the DSC thermograms obtained with a heating rate of $50 \mathrm{~K} / \mathrm{min}$ for a $50 \mathrm{~nm}$ Ni film on amorphous Si. Four peaks are observed and corresponds to different steps of the silicide formation. This illustrates the potential of DSC to reveal the initial steps of reaction at an interface from a single reacting interface on a Si substrate. In order to identify the origin of these peaks, samples were prepared by stopping the DSC experiments after each peak and the phase identification was performed by XRD. The two peaks indicated by arrows were attributed to the growth of $\delta-\mathrm{Ni}_{2} \mathrm{Si}$. Moreover, integration of these two peaks gives approximately the Gibbs free energy of formation of $\delta-\mathrm{Ni}_{2} \mathrm{Si}(-49 \mathrm{~kJ} / \mathrm{g}$.atoms) [64].

In accordance with former results [12,55,57,65], two DSC peaks are thus associated to the formation of one phase $\left(\delta-\mathrm{Ni}_{2} \mathrm{Si}\right)$. The first DSC peak corresponds to the nucleation of $\mathrm{Ni}_{2} \mathrm{Si}$ and its subsequent lateral growth up to a continuous layer as indicated by the insert. The second peak results from the one dimension thickening of this continuous layer up to the full consumption of the film. 

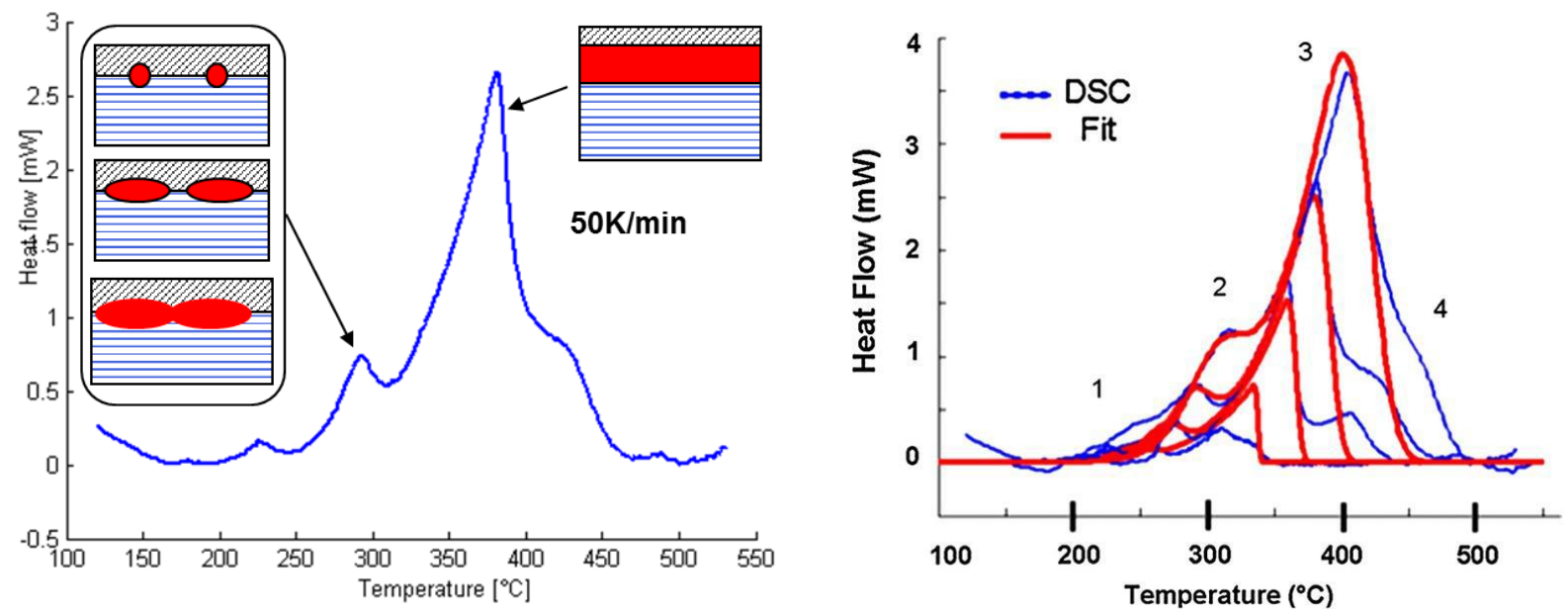

Fig. 6: Reaction between a Ni $(50 \mathrm{~nm})$ on a-Si $(300 \mathrm{~nm})$ bilayer deposed on a (100)Si substrate: (a) DSC thermogram obtained for the reaction between $50 \mathrm{~nm} \mathrm{Ni}$ film and the a-Si/Si(100) substrate. The insert indicates the mechanisms responsible for the peaks corresponding to the growth of $\delta-\mathrm{Ni}_{2} \mathrm{Si}$. (b) Comparison between the DSC thermograms obtained with four heating rates $(10,25,50,100 \mathrm{~K} / \mathrm{min})$ and a simulation based on a numerical integration of the model (Eq. 7-9). The simulated curve was convoluted with a Gaussian to take into account the DSC instrumental function.

In order to determine the kinetics of lateral growth, the DSC measurements for several heating ramps were simulated using the Coffey's model (red lines in Fig. 6.b). The model developed by Coffey et al. [12] assumes the nucleation of the new phase at the interface and its lateral growth, the volume fraction being expressed as:

$$
\frac{d X v}{d t}=\left(\frac{d X_{a}}{d t}\right) \frac{L}{L_{\max }}+\left(\frac{d L}{d t}\right) \frac{X_{a}}{L_{\max }} .
$$

where $L$ is the thickness of $\delta-\mathrm{Ni}_{2} \mathrm{Si}, L_{\max }$ the maximum thickness that $\delta-\mathrm{Ni}_{2} \mathrm{Si}$ can reach (for sequential growth in thin film, $L_{\max }$ is proportional to the Ni thickness through the atomic volume of $\mathrm{Ni}$ and $\mathrm{Ni}_{2} \mathrm{Si}$ ), $d L / d t$ is the one-dimensional growth rate, $X_{a}$ is the area fraction of $\delta-\mathrm{Ni}_{2} \mathrm{Si}$ at the interface, $d X_{a} / d t$ is the change in the area fraction as a function of time. The lateral growth of the precipitates takes place in two dimensions until the precipitates impinge upon each other. The impingement can be taken into account via the concept of extended volume [66] and for simplicity, it was assumed that the nucleation barriers was low and that a fixed density of nucleation sites (n) exists at the interface. Moreover, the precipitates were chosen to be cylinders with an initial height $\mathrm{L}_{0}$ and radius $\mathrm{r}_{0}$. The area fraction when the precipitates of cylindrical shape (radius $r$ ) are in contact is given by:

$$
X_{a}=1-\exp \left(-n \pi r^{2}\right)
$$

The lateral growth rate of these precipitates was also assumed to be limited by the reaction at the interface and can be expressed as follows:

$$
\frac{d r}{d t}=K_{L G}=K_{L G 0} \exp \left(-\frac{E_{L G}}{k_{B} T}\right)
$$

where $\mathrm{k}_{\mathrm{B}}$ is the Boltzman constant, $\mathrm{T}$ is the temperature, $\mathrm{K}_{\mathrm{LG} 0}$ and $\mathrm{E}_{\mathrm{LG}}$ are the pre-exponential factor and the activation energy of the lateral growth of the precipitates. The thickening of the precipitates was modelled using the Deal and Grove model that will be detailed later. The modeled kinetic parameters are given in Table 1 for lateral growth. For comparison, the values for the 
formation of $\mathrm{Pd}_{2} \mathrm{Si}$ obtained from similar experiments are also reported in Table 1 . The mobility of the interface are relatively close to each other in the $\mathrm{Ni}$ and Pd systems. More studies on other systems should be done to confirm this tendency.

\begin{tabular}{|c|c|c|c|c|c|}
\hline system & $\mathrm{L}_{0}[\mathrm{~nm}]$ & $\mathrm{r}[\mathrm{nm}]$ & $\mathrm{N}\left[\mathrm{site}_{\mathrm{nm}}{ }^{2}\right]$ & $\mathrm{K}_{\mathrm{i} 0}[\mathrm{~cm} / \mathrm{s}]$ & $\mathrm{E}_{\mathrm{i}}[\mathrm{eV}]$ \\
\hline $\mathrm{Ni} / \alpha-\mathrm{Si}$ & 7 & 5 & $310^{-5}$ & 13 & 0.85 \\
\hline $\mathrm{Pd} /(001) \mathrm{Si}$ & 5 & 20 & $510^{-4}$ & 15 & 0.85 \\
\hline
\end{tabular}

Table 1. Values of the parameters used in Eq. 7-9 to describe the lateral growth of $\mathrm{Pd}_{2} \mathrm{Si}$ and $\delta-\mathrm{Ni}_{2} \mathrm{Si}$.

Lateral growth: comparison between models and morphologies determined by TEM. A further evidence of the lateral growth was obtained recently: El Kousseifi et al. [67,68] found the presence of a low density of NiSi particles at the $\theta-\mathrm{Ni}_{2} \mathrm{Si} / \mathrm{Si}(100)$ interface during the reaction of 10 $\mathrm{nm} \mathrm{Ni}(10 \% \mathrm{Pt})$ film with a (100) Si substrate. Fig. 7 shows TEM images with NiSi precipitates located at the interface between the $\theta-\mathrm{Ni}_{2} \mathrm{Si}$ and the $\mathrm{Si}$ substrate. The precipitates are separated by distances ranging from 0.8 to $1.2 \mu \mathrm{m}$ and the average distance between them is about $1.1 \mu \mathrm{m}$. The density of the NiSi precipitates is thus relatively low (around 1 nucleus $/ \mu \mathrm{m}^{2}$ ). Fig. 7 shows that they are slightly different but their overall shape is similar. They have roughly the shape of cylinders with a high aspect ratio since their diameter vary from 120 to $380 \mathrm{~nm}$ while their thickness ranges from 13 to $17 \mathrm{~nm}$. Note that the particle did not consume the whole $\theta-\mathrm{Ni}_{2} \mathrm{Si}$ phase in thickness. Their size is too large to correspond to the nucleation nuclei but their characteristics (shape, density...) indicate a fast lateral growth compared to the normal growth.
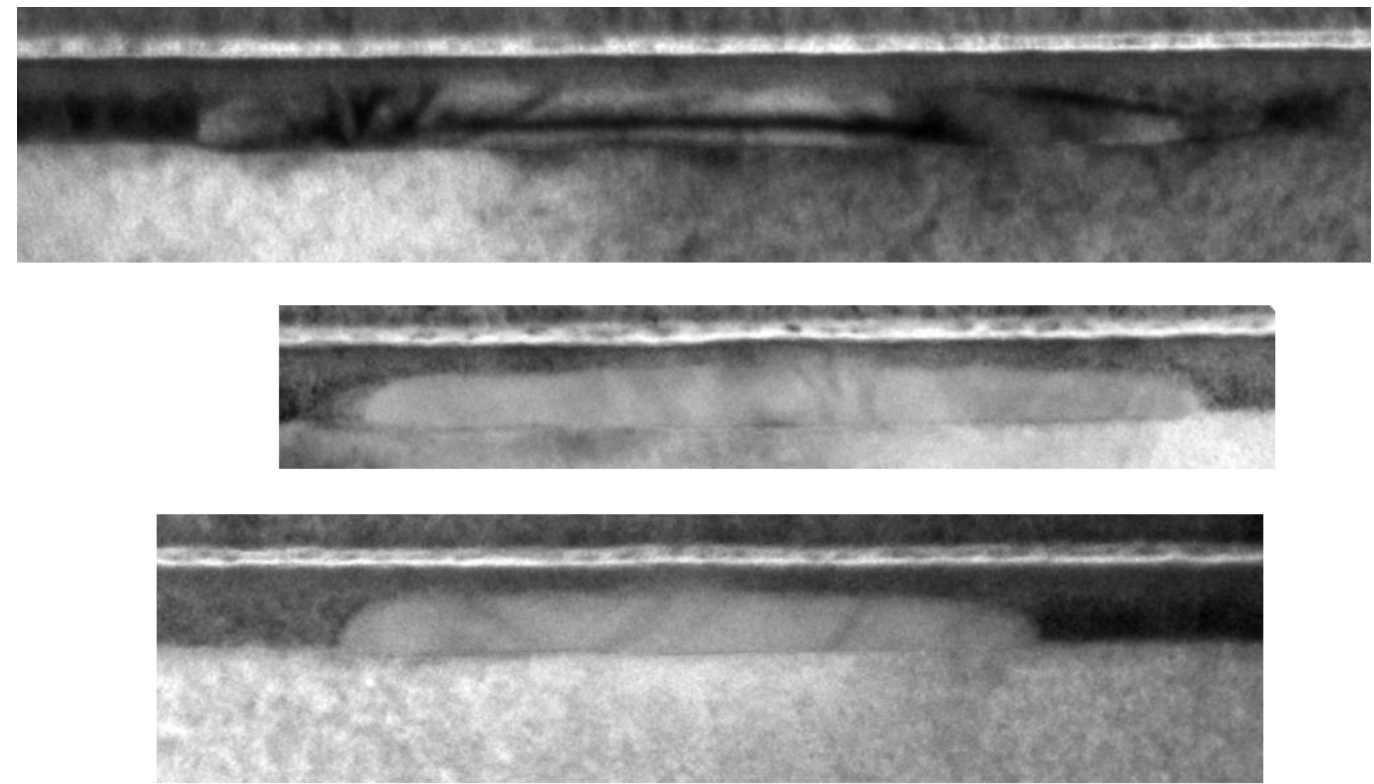

\section{$50 \mathrm{~nm}$}

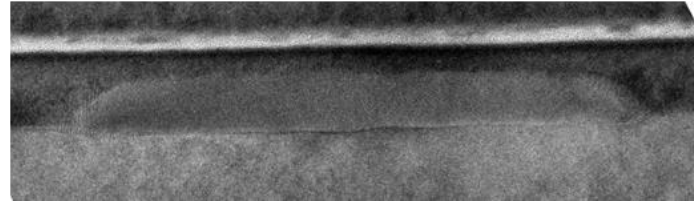

Fig. 7: High magnification conventional TEM micrographs of the $250{ }^{\circ} \mathrm{C}$ annealed $\mathrm{Ni}(10 \% \mathrm{Pt})$ sample observed in cross-section along a $\langle 110\rangle$ Si direction. Adapted from Ref. [68].

Even if several experimental studies [12,27,55-60,65] give evidence for lateral growth, the shape of the entire precipitates was not reported in these studies while the TEM results in Fig. 7 provide a direct observation of the particle shapes. The shape of precipitates as well as their dimensions are in accordance with the existing models $[12,59,61-63,67]$ that are presented in Fig. 8. Indeed these 
models predict a roughly elliptical or cylindrical shape with a large aspect ratio between the diameter of the precipitates and their thickness. The TEM images (Fig. 7) allow a direct comparison with these models and the analytical solutions $[61,63,67,68]$ have been used to fit the TEM images instead of the numerical simulation developed by Lucenko et al. [11] and Vovk et al. [9]. Moreover Fig. 7 shows that the position of the NiSi precipitates is asymmetrical toward the $\theta-\mathrm{Ni}_{2} \mathrm{Si} / \mathrm{Si}$ interface. Indeed, the lateral growth of NiSi precipitates is more developed on the side of $\theta-\mathrm{Ni}_{2} \mathrm{Si}$ phase than on the $\mathrm{Si}$ side. This asymmetrical shape can be explained by the mass conservation during the reaction $\left(\theta-\mathrm{Ni}_{2} \mathrm{Si}+\mathrm{Si} \rightarrow 2 \mathrm{NiSi}\right)$ taking into account the atomic volumes of the different phases. The edges of the NiSi precipitates have also an asymmetrical lens shape and correspond to the triple junction between the three phases $\left(\theta-\mathrm{Ni}_{2} \mathrm{Si} / \mathrm{NiSi} / \mathrm{Si}\right)$. Even if their exact shape is difficult to determine, Fig. 9 show that the triple junction between $\theta-\mathrm{Ni}_{2} \mathrm{Si}, \mathrm{NiSi}$, and $\mathrm{Si}$ are not always the same. Indeed two main type of triple junction are observed: the $\theta-\mathrm{Ni}_{2} \mathrm{Si} / \mathrm{Si}$ interface can be straight or curved (Fig. 9).

El Kousseifi et al. [67] have extended the model of Klinger et al. [61] to take into account this volume change. The main assumptions of these models are: (1) the asymmetrical position of the NiSi particle with respect to the $\theta-\mathrm{Ni}_{2} \mathrm{Si} / \mathrm{Si}$ interface is due to the matter conservation and to the volume change during the reaction between $\theta-\mathrm{Ni}_{2} \mathrm{Si}$ and $\mathrm{Si},(2)$ the mechanical equilibrium of the interfacial energies is responsible for the particle shape (3) the $\mathrm{Ni}$ and $\mathrm{Si}$ interdiffusion along interfaces is assumed to drive the kinetics of the fast lateral growth; the elements $\mathrm{Ni}$ and $\mathrm{Si}$ are thus considered to diffuse in opposite directions along the $\mathrm{Si} / \mathrm{NiSi}$ and $\theta-\mathrm{Ni}_{2} \mathrm{Si} / \mathrm{NiSi}$ interfaces, and (4) the driving force for the flux of the diffusing element along the interface is the gradient of the chemical potential difference due to the gradient of curvature. In these models $[61,63,67,68]$, the steady state shape of the moving interface and its velocity are calculated from the flux and the mass conservation condition across the moving interface and the boundaries.

a)

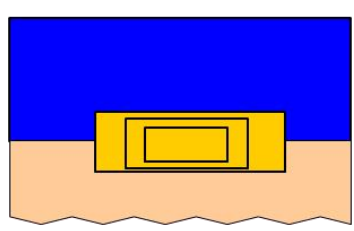

Coffey et al., 1989 b)

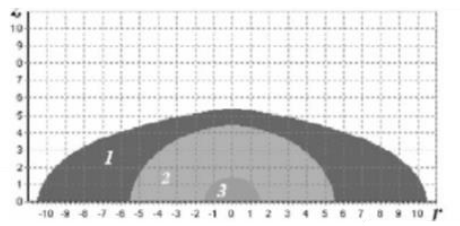

Lucenko et al., 2003 c)

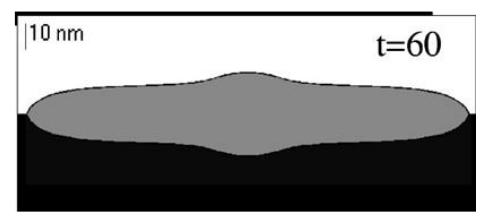

Vovk et al. 2004

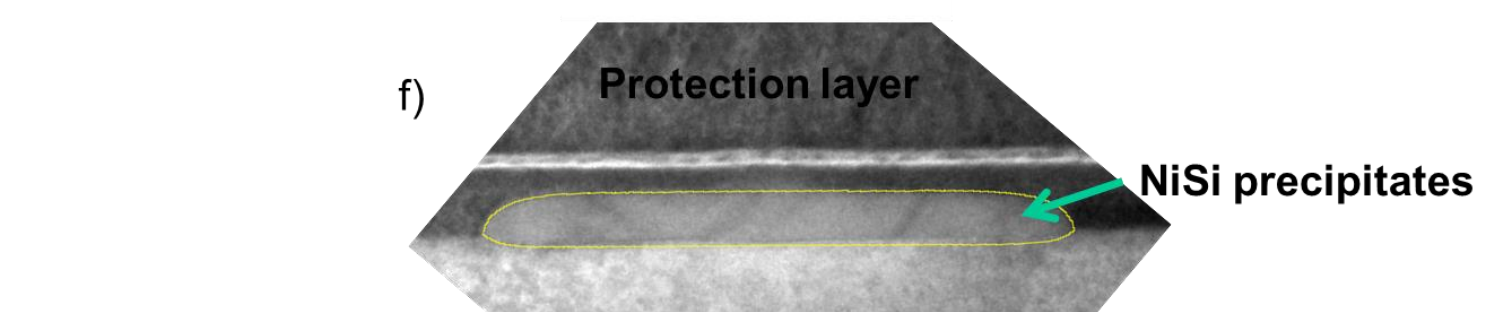

d)

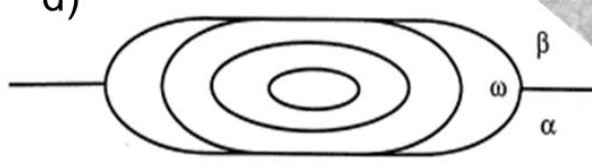

Klinger et al. 1998 / Chuang et al. 1973
Substrat Si

e)

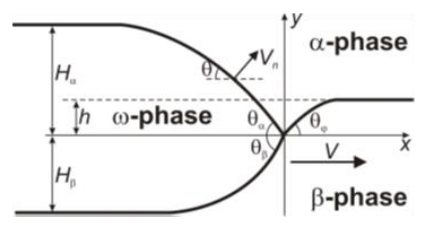

Pasichnyy and Gusak, 2008

Fig. 8: NiSi precipitate at the $\theta-\mathrm{Ni}_{2} \mathrm{Si} / \mathrm{Si}(100)$ interface together with different models of lateral growth.

In addition to reproduce the global shape of the precipitaes, the model developed by Pasichnyy and Gusak [63] allows the initial interface $\left(\theta-\mathrm{Ni}_{2} \mathrm{Si} / \mathrm{Si}\right)$ to be deformed and to become curved. The assumptions of this model [63] are relatively similar to the one of El Kousseifi et al. [67]: (1) asymmetrical position of the growing particle due to the matter conservation and to the volume change during the reaction, (2) mechanical equilibrium of the interfacial energies and (3) $\mathrm{Ni}$ and $\mathrm{Si}$ 
interdiffusion along interfaces with a Darken diffusion coefficient (D). However the diffusion is not driven by the gradient of curvature but by a gradient of concentration along the interface. The displacement speed of the interface $V_{n}^{\alpha \omega}$ is also assumed to be proportional to the difference of concentration across the interface. Fig. 9 shows that the two models $[63,67]$ allows well reproducing the shape and dimensions of the precipitates while the model of Pasichnyy and Gusak [63] can additionally fit the two type of triple junction [68]. The good agreement between the simulation and the experiments (Fig. 9) allows to validate the assumptions of the models: i.e. lateral growth with mass conservation, mechanical equilibrium at the triple junction, and diffusion along the interfaces. The comparison between experiments and models allows to access parameters that are difficult to measure such as diffusion coefficient along the interphases and interfacial energies. For diffusion, the mobility for both $\mathrm{Si}$ and $\mathrm{Ni}$ at the interface was determined to be around $10^{22} \mathrm{at} /(\mathrm{s} . \mathrm{J})$ for the $\mathrm{El}$ Kousseifi model [67]. These mobilities have dimensions of at/(s.J) instead of at/(m.s.J) because the flux is a surface (or interface) flux with dimensions of at/(m.s). From the model of Pasichnyy and Gusak [63,68], the interdiffusion coefficients were found to vary from 5 to $200 \mathrm{~nm}^{2} / \mathrm{s}$ depending on the interface nature and if a curved or straight interface is considered. Even if these are indirect measurement, they give estimate of the diffusion at interphases that is difficult to study [69].

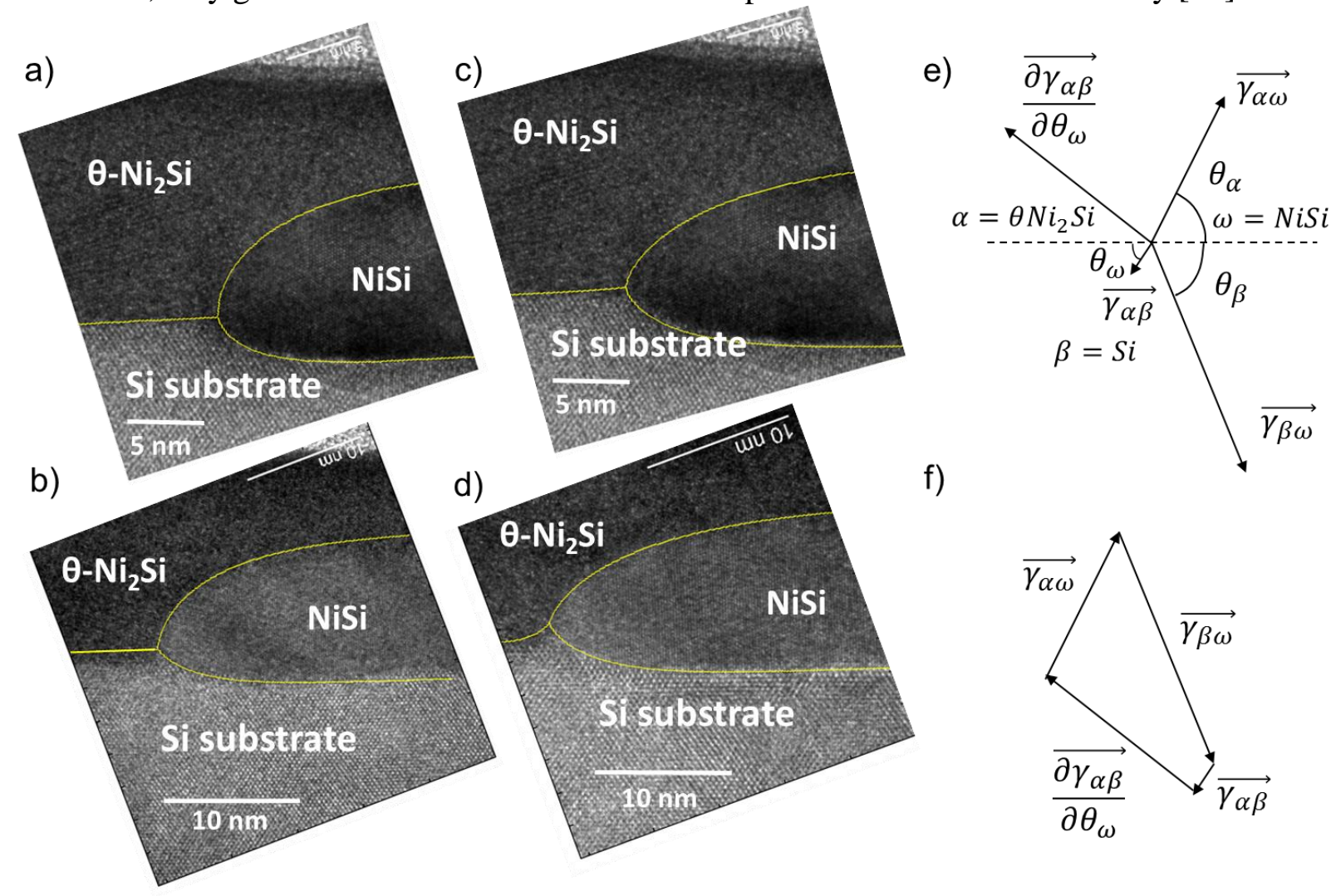

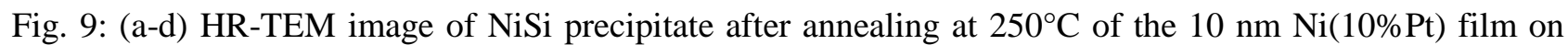
(100)Si: the sample was observed in cross-section along a $\langle 110>\mathrm{Si}$ direction. with a with a straight $\theta-\mathrm{Ni} 2 \mathrm{Si} / \mathrm{Si}$ interface is observed in (a) and (c) while the $\theta-\mathrm{Ni}_{2} \mathrm{Si} / \mathrm{Si}$ interface is curved in (b) and (d). Yellow curves correspond to the model of El Kousseifi et al. [67] in (a) and (b) or the model of Pasichnyy and Gusak [63] in (c) and (d). (e) and (d) are schematics of the interfacial energies in the presence of a torque term for the epitaxial $\theta-\mathrm{Ni}_{2} \mathrm{Si} / \mathrm{Si}$ interface.

Concerning the interface energies, the fit leads to values within the same order of magnitude (typically a few $\mathrm{mJ} / \mathrm{m}^{2}$ ) for all the interfaces as shown in Table 2 . However the epitaxial $\theta-\mathrm{Ni}_{2} \mathrm{Si} / \mathrm{Si}$ interface is coherent or at least semicoherent and should have a much lower energy than the ones for the $\mathrm{NiSi} / \mathrm{Si}$ and $\mathrm{NiSi} / \theta-\mathrm{Ni}_{2} \mathrm{Si}$ interfaces that should be incoherent. An important point of the models of Klinger et al. [61] and El Kousseifi et al. [67] is that the mechanical equilibrium is assumed only along the initial $\theta-\mathrm{Ni}_{2} \mathrm{Si} / \mathrm{Si}$ interface and not in the direction perpendicular to this interface. Moreover 
this model supposes that the $\theta-\mathrm{Ni}_{2} \mathrm{Si} / \mathrm{Si}$ interface is imposed to be straight that is in contradiction with the experimental observations and thus cannot fit the second type of triple line (Fig. 9). The model developed by Pasichnyy and Gusak [63] allows the initial interface to be deformed and to become curved. For this model, the energy of the $\theta-\mathrm{Ni}_{2} \mathrm{Si} / \mathrm{Si}$ interface was also set to a low value in order to be representative of the expected interface energies as explained before. However this impose almost equal values for the $\theta-\mathrm{Ni}_{2} \mathrm{Si} / \mathrm{NiSi}$ interface and the $\mathrm{NiSi} / \mathrm{Si}$ interface since in the Pasichnyy and Gusak model, a true (i.e. vectors) mechanical equilibrium is assumed:

$$
\vec{\gamma}_{\alpha \beta}+\vec{\gamma}_{\alpha \omega}+\vec{\gamma}_{\beta \omega}=\overrightarrow{0}
$$

Indeed if this classical equation for the mechanical equilibrium (Eq. 10) holds, the forces should be almost equal and opposite $\vec{\gamma}_{\alpha \omega} \sim \vec{\gamma}_{\beta \omega}$ since $\vec{\gamma}_{\alpha \beta} \ll \vec{\gamma}_{\alpha \omega}, \vec{\gamma}_{\beta \omega}$. However there is no reasons why the two interface energies, $\vec{\gamma}_{\alpha \omega}$ and $\vec{\gamma}_{\beta \omega}$, are equal since these interfaces are different. In order to explain this paradox, one should remember that the classical equation is an approximation and neglects the torque term. Indeed the Herring's equation that is valid if the interfacial energies are orientation dependent can be expressed as [70,71]:

$$
\sum_{j=1}^{3}\left(\gamma_{j} \vec{b}_{j}+\frac{\partial \gamma_{j}}{\partial \theta_{j}} \vec{n}_{j}\right)=\overrightarrow{0}
$$

where $\gamma_{j}$ is the excess free energy of the jth boundary, $\vec{n}_{j}$ is the unit boundary normal of the boundary, $\vec{b}_{j}$ is a unit vector lying in the jth boundary and perpendicular to the triple line. The derivative terms are referred to as torque terms and reflect the dependence of interface energy on orientation or the resistance of an interface to rotation about the triple junction (Fig. 9.e-f ). The torque terms can be quite high for coherent interface [72] and may explain this apparent paradox. Indeed Fig. 9 shows that one can construct a configuration that respects the observed angles and different values of the interfacial energies expected for the different interfaces if one assumed a large torque term for the epitaxial interface between $\theta-\mathrm{Ni}_{2} \mathrm{Si}$ and $\mathrm{Si}$. The presence of this large torque term may also explain to some extent why the $\theta-\mathrm{Ni}_{2} \mathrm{Si} / \mathrm{Si}$ interface is curved close to the triple line since the torque term exerts a force perpendicular to this interface. In order to fully understand the lateral growth, one may thus have to take into account the torque term.

\begin{tabular}{ccc}
\hline Interface & $\gamma\left[\mathrm{J} / \mathrm{m}^{2}\right]$ for $[67]$ & $\gamma\left[\mathrm{J} / \mathrm{m}^{2}\right]$ for $[62]$ \\
\hline $\mathrm{NiSi} / \mathrm{Si}$ & 1.2 & 1 \\
\hline $\mathrm{NiSi} / \theta-\mathrm{Ni}_{2} \mathrm{Si}$ & 2.5 & 1 \\
\hline $\mathrm{Si} / \theta-\mathrm{Ni}_{2} \mathrm{Si}$ & 0.3 & 0.1 \\
\hline
\end{tabular}

Table 2: Interfacial energies used in the model of Pasichnyy and Gusak [63] and the model of El Kousseifi et al. [67].

The comparison between experiments and models allows thus to highlight the important parameters for the lateral growth even if there are still some points to clarify. Further analysis and models including at least the torque term may be needed in order to gain a better understanding of the parameters and the phenomena responsible for the lateral growth. This should be important for the actual microelectronics devices in which the thickness of the silicide used as contact are in the order or below $10 \mathrm{~nm}$ and thus the formation of silicide should be controlled mainly by nucleation and lateral growth. In order to have reproducible and reliable process for the contact formation by solid state reaction, these phenomena should be understood and controlled because they can impact the behaviour and the properties of the contacts.

Normal growth. In the former paragraphs, the role of nucleation and lateral growth was emphasized. However for films thicker than about $10 \mathrm{~nm}$, the normal growth constitutes the main part of the growth as shown in the DSC measurement (Fig. 6) where the main peak for the $\delta-\mathrm{Ni}_{2} \mathrm{Si}$ corresponds to this 
normal growth. Experimental results coupled with model will be now presented to gain some understanding on the mechanisms governing this type of growth and on the effect of impurities or additive elements on it.

Linear-parabolic growth. In a precedent paragraph, the simulation of the DSC measurement using the Coffey model for lateral growth was presented. Nemouchi et al. [27] have modelled the thickening (=normal growth) of $\delta-\mathrm{Ni}_{2} \mathrm{Si}$ by taking into account DSC thermograms obtained with four heating rates $(10,25,50,100 \mathrm{~K} / \mathrm{min})$ and isothermal in situ XRD measurements such as the one in Fig 10. Fig. 10.b shows the variation with time of the square of the normalized XRD intensities of the $\mathrm{Ni} 111, \mathrm{Ni}_{2} \mathrm{Si} 020$, and $\mathrm{NiSi} 211$ lines for an isothermal heat treatment at $210^{\circ} \mathrm{C}$ for the same 50 $\mathrm{nm} \mathrm{Ni}$ film on amorphous Si (Fig. 10.a). The formation of $\delta-\mathrm{Ni}_{2} \mathrm{Si}$ and $\mathrm{NiSi}$ is sequential: $\delta-\mathrm{Ni}_{2} \mathrm{Si}$ grows at the expense of $\mathrm{Ni}$ and NiSi starts to grow only when $\mathrm{Ni}$ is totally consumed. In Fig. 10.b, the square of the XRD intensities varies linearly with time indicating that, for this heat treatment, the growth of $\delta-\mathrm{Ni}_{2} \mathrm{Si}$ and $\mathrm{NiSi}$ appears to be controlled by diffusion in agreement with former reports $[21,52]$.
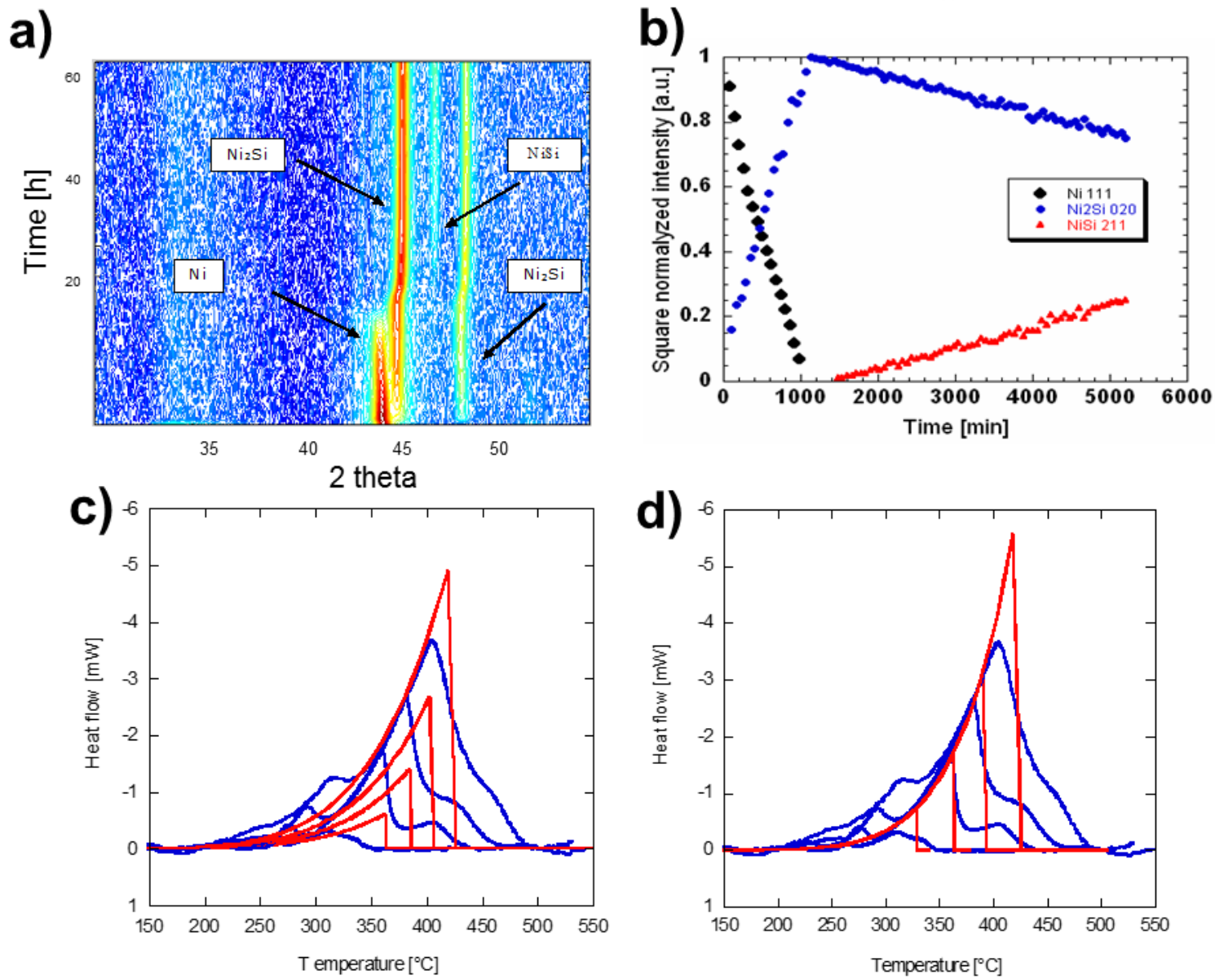

Fig. 10: Reaction between a Ni (50 nm) on a-Si (300 nm) bilayer deposed on a (100)Si substrate. (a) XRD intensity as a function of diffraction angle and time during an isothermal heat treatment at $210^{\circ} \mathrm{C}(\mathrm{b})$ Variation of the square of the normalized intensities of the $\mathrm{Ni} 111, \mathrm{Ni}_{2} \mathrm{Si} 020$ and NiSi $211 \mathrm{X}$-ray diffraction lines as a function of annealing time, (c) Comparison between the DSC thermograms and a simulation based on a diffusion controlled growth, (d) Comparison between the DSC thermograms and a simulation based on a reaction controlled growth. From Ref. [27,73].

Taking into account the results obtained by in situ XRD, the DSC peak (dL/dt) were first modelled according to a diffusion controlled growth (Fig. 10.c) but it was not possible to fit all the ramps using the same kinetic parameters $\left(\mathrm{D}_{0}\right.$ and $\left.\mathrm{Q}\right)$ for normal growth [27]. Fig. 10.d shows that a reaction 
controlled growth allows to reproduce the peaks for the normal growth. In order to further improve the fit, the linear parabolic law in its derivative form was thus used (Fig. 6). The kinetic parameters controlling the growth of the $\mathrm{M}_{2} \mathrm{Si}$ layer have thus been extracted from experimental data using a model that considers both interfacial reactions and atom diffusion through the growing $\mathrm{M}_{2} \mathrm{Si}$ layer, i.e the Deal and Groves growth law (linear-parabolic law for isotherm) [74]:

$$
\frac{d L}{d t}=\frac{K_{N G} D_{N G}}{L K_{N G}+D_{N G}} \frac{\Delta G_{N G}}{k_{B} T} .
$$

$L$ is the thickness of the $\mathrm{M}_{2} \mathrm{Si}$ layer and $k_{B}$ the Boltzmann constant. $\Delta G_{N G}$, the driving force for the growth, was assumed to be constant over the small experimental range of temperature. $K_{N G}$ is the average effect of reactions at both interfaces and $D_{N G}$ is the effective effect of both $\mathrm{M}$ and $\mathrm{Si}$ diffusion on the $\mathrm{M}_{2}$ Si layer growth. $K_{N G}$ and $D_{N G}$ could be obtained using the DSC measurement only, but for a better reliability, Eq. 12 with the same parameter values was used to fit all XRD and DSC measurements. Indeed, XRD and DSC measurements were performed under different conditions (isotherm and temperature ramp annealing, respectively) and are related to different physical /chemical properties ( $\delta-\mathrm{Ni}_{2} \mathrm{Si}$ crystal structure for XRD and formation enthalpy for DSC). Since both $\mathrm{D}_{N G}$ and $\mathrm{K}_{N G}$ are thermally activated, Eq. 12 can be integrated only for an isothermal heat treatment. For isochronal treatments, numerical integration should be used. The values of $\mathrm{K}_{N G}$ and $\mathrm{D}_{N G}$ were obtained respectively by fitting the DSC experiments with an interface controlled growth law and XRD experiments with a parabolic law. They were then slightly adjusted in order to obtain the best fit for both XRD and DSC with Eq. 12. The final values are:

$$
K_{N G}=0.25 \exp \left(\frac{-0.8}{k_{B} T}\right) \mathrm{cm} / \mathrm{s} \text { and } D_{N G}=1.67 \exp \left(\frac{-1.5}{k_{B} T}\right) \mathrm{cm}^{2} / \mathrm{s} \text {. }
$$

As shown above, it is needed to use the linear parabolic law to fit the XRD and the DSC measurement of the normal growth of $\delta-\mathrm{Ni}_{2} \mathrm{Si}$. We will now discussed in more details this law and its implication in microelectronics. The linear parabolic law is obtained by considering two phenomena that can control the growth. The first one is the diffusion across the growing $\delta-\mathrm{Ni}_{2} \mathrm{Si}$. If one consider that $\mathrm{Ni}$ is the main diffusing species [8] and that the chemical potential gradient is constant in $\mathrm{Ni}_{2} \mathrm{Si}$, the flux due to diffusion is proportional to $\mathrm{D}_{N G}\left(\mu_{2}-\mu_{1}\right) / \mathrm{L}$, where $\mathrm{D}_{N G}$ is the interdiffusion coefficient, $\mathrm{L}$ the thickness of $\delta-\mathrm{Ni}_{2} \mathrm{Si}, \mu_{1}$ and $\mu_{2}$ the chemical potential of $\mathrm{Ni}$ respectively at the $\mathrm{Ni} / \mathrm{Ni}_{2} \mathrm{Si}$ interface and at the $\mathrm{Ni}_{2} \mathrm{Si} / \mathrm{Si}$ interface in $\mathrm{Ni}_{2} \mathrm{Si}$. The second phenomenon is the interfacial reaction for which the flux is proportional to $K_{N G} .\left(\mu_{3}-\mu_{2}\right)$, where $K$ is the interfacial rate constant and $\left(\mu_{3}-\mu_{2}\right)$ the difference in chemical potential at the moving interface. By equating these two fluxes and applying the law of conservation of matter, one obtains the Deal and Groves law [74] in its differential form (equivalent to Eq. 12).

$$
\frac{d L}{d t}=\frac{K_{N G} D_{N G}}{K_{N G} L+D_{N G}} \frac{\mu_{3}-\mu_{1}}{k_{B} T}=\frac{1}{\frac{L}{k_{D}}+\frac{1}{k_{I}}} .
$$

where $k_{D}$ et $k_{I}$ are the diffusion and interface growing rates taking into account both kinetics ( $\mathrm{K}_{N G}$ or $\left.\mathrm{D}_{N G}\right)$ and thermodynamics term $\left(\mu_{3}-\mu_{1}\right)$. The growth of the silicide is thus controlled not only by the usual phenomenon of diffusion but also by the reaction at the interface. These results (Fig. 10) show that, with the relatively fast heating ramp used in DSC, the growth is mainly limited by the interfacial reaction while isothermal heat treatment at relatively low temperature leads to a growth controlled by diffusion. This can be understood if one takes into account the two limiting cases of Eq.14. If the thickness of the growing phase is much inferior to a transition thickness defined by $\mathrm{L}_{\mathrm{t}}=\frac{\mathrm{D}}{\mathrm{K}}$, the growth will be mainly controlled by the interfacial reaction while in the other case it will be controlled by diffusion. The relation between $L_{t}$ and the temperature $T_{t}$ is the following: 


$$
\mathrm{L}_{\mathrm{t}}=\frac{\mathrm{D}_{0}}{\mathrm{~K}_{0}} \exp \left(\frac{-\left(\mathrm{E}_{\mathrm{D}}-\mathrm{E}_{\mathrm{i}}\right)}{\mathrm{k}_{\mathrm{B}} \mathrm{T}_{\mathrm{t}}}\right) \text { or } \mathrm{T}_{\mathrm{t}}=\frac{\mathrm{E}_{\mathrm{D}}-\mathrm{E}_{\mathrm{i}}}{\mathrm{k}_{\mathrm{B}} \ln \left(\frac{\mathrm{D}_{0}}{\mathrm{~L}_{\mathrm{t}} \mathrm{K}_{0}}\right)} \text {. }
$$

Fig. 11 shows the variation of $\mathrm{T}_{\mathrm{t}}$ as a function of $\mathrm{L}_{\mathrm{t}}$ for $\delta-\mathrm{Ni}_{2} \mathrm{Si}$. In this figure, two domains can be defined: one where the growth is mainly controlled by interfacial reaction and one where it is mainly controlled by diffusion. It should be emphasized that the growth is always controlled by both phenomena but will be mainly controlled by one of them if the measurement is performed far from the boundary between the two domains. The variation of the thickness as a function of temperature for two of the DSC ramps (10 and $100 \mathrm{~K} / \mathrm{min})$ and two of the XRD isotherms $\left(210\right.$ and $\left.260^{\circ} \mathrm{C}\right)$ have also been schematically reported in Fig. 11. It can be seen that the XRD experiment at the lowest temperature is mainly in the diffusion controlled domain while the DSC experiment with the 100 $\mathrm{K} / \mathrm{min}$ ramp is clearly in the interface-controlled domain. In a general manner these results show that the interface-controlled regime will dominate at low thickness and high temperature. This is quite important in microelectronics where the thickness of films is continuously decreasing and where heat treatments are performed using fast heating ramps (rapid thermal process, flash annealing). The knowledge of the interface mobilities is also important to understand the sequential growth observed in thin film [75-77]. However one should be aware before using a very simple view of the growth such as the interface/diffusion controlled model that there might be quite a lot of phenomena (non equilibrium defects, grain growth, change of texture...) that can influence the growth especially when heat treatments are performed very far from equilibrium or quasi equilibrium.

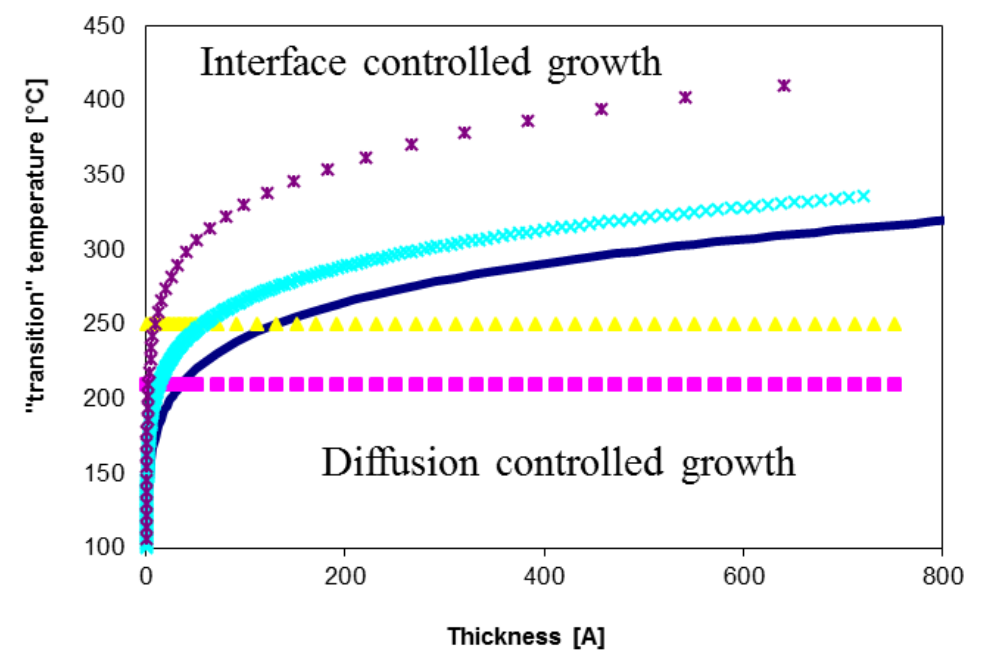

Fig. 11: Variation of $\mathrm{T}_{\mathrm{t}}$ as a function of $\mathrm{L}_{\mathrm{t}}$ for $\delta-\mathrm{Ni}_{2} \mathrm{Si}$ showing the two domains of growth: interfacial reaction and diffusion. The variation of the thickness as a function of temperature for two of the DSC ramps (10 and $100 \mathrm{~K} / \mathrm{min}$ ) and two of the XRD isotherms $\left(210\right.$ and $\left.260^{\circ} \mathrm{C}\right)$ is also shown.

Effect of additive element or diffusion barrier on the normal growth. In a recent work, Mangelinck et al. [78] have investigated the role of diffusion barrier on the normal growth. More precisely they studied the effect of a diffusion barrier on the kinetics of the $\delta$-Ni2Si phase formation measured by in situ $\mathrm{X}$ ray diffraction during isothermal annealing of pure Ni film, Ni film with a W barrier, and $\mathrm{Ni}(5 \% \mathrm{Pt})$ films. 

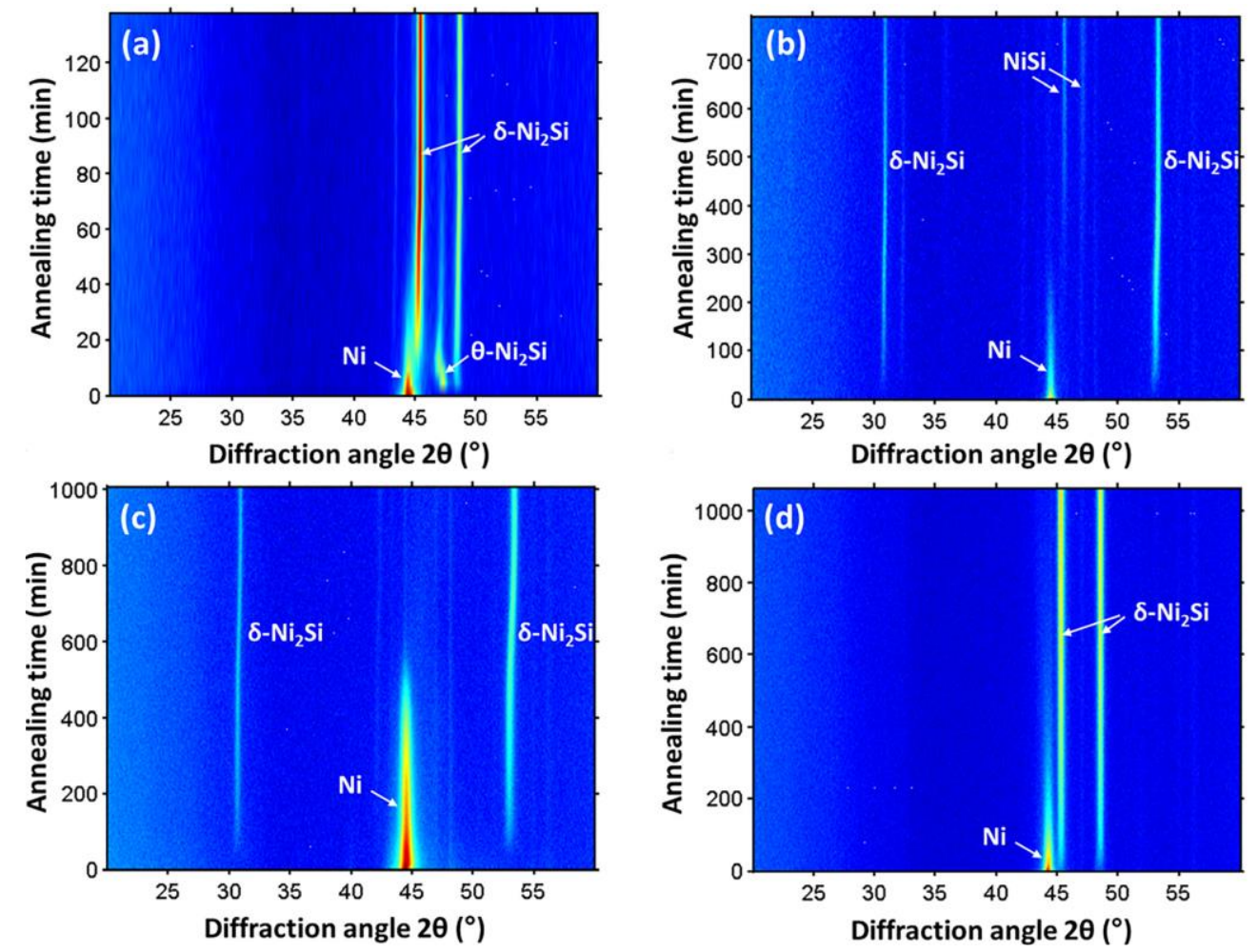

Fig. 12: In situ XRD measurement at $270 \mathrm{C}$ for (a) $50 \mathrm{~nm} \mathrm{Ni}$, (b) $50 \mathrm{~nm} \mathrm{Ni} / 0.5 \mathrm{~nm} \mathrm{~W}$, (c) $50 \mathrm{~nm} \mathrm{Ni} / 1 \mathrm{~nm} \mathrm{~W}$, and (d) Ni(5\%)Pt films on Si(100). From Ref. [78].

Fig. 12 shows the XRD intensity as a function of the 2 theta angle and the time for (a) $50 \mathrm{~nm} \mathrm{Ni}$, (b) $50 \mathrm{~nm} \mathrm{Ni} / 0.5 \mathrm{~nm} \mathrm{~W}$, (c) $50 \mathrm{~nm} \mathrm{Ni} / 1 \mathrm{~nm} \mathrm{~W}$, and (d) Ni(5\%)Pt films on Si(100) during in situ annealing at $270^{\circ} \mathrm{C}$. In all cases, the $\delta-\mathrm{Ni}_{2} \mathrm{Si}$ phase is growing at the extent of the metal film (Ni or $\mathrm{Ni}(5 \% \mathrm{Pt})$ ). When the metal film has been consumed, NiSi grows (this can only be seen in Fig. 12.b but it has been also observed for the other cases in other in situ XRD experiments not shown here). Note that the time scale is not the same for all the measurements and that the time to complete the formation of $\delta-\mathrm{Ni}_{2} \mathrm{Si}$ is largely increased in the case of the presence of a barrier or the alloy metal film. In order to compare the kinetics of $\delta-\mathrm{Ni}_{2} \mathrm{Si}$, the normalized intensity of the XRD peaks that should be proportional to the $\delta-\mathrm{Ni}_{2} \mathrm{Si}$ thickness are reported as a function of time in Fig. 13 for the different cases. Fig. 13. a shows the $\delta-\mathrm{Ni}_{2} \mathrm{Si}$ thickness as a function of time and confirms that the $\mathrm{W}$ barrier or the presence of $\mathrm{Pt}$ in the $\mathrm{Ni}$ film delays to a large extent the formation of $\delta-\mathrm{Ni}_{2} \mathrm{Si}$. Moreover the log-log plot in Fig. 13.b indicates that the variation of the thickness with time show a different behaviour for the samples with $\mathrm{W}$ barrier than for the pure $\mathrm{Ni}$ and the $\mathrm{Ni}(5 \% \mathrm{Pt})$ samples. Indeed the pure $\mathrm{Ni}$ and $\mathrm{Ni}(5 \% \mathrm{Pt})$ samples show a parabolic growth as indicated by the $\mathrm{t}^{1 / 2}$ slope while the barrier samples have a more complex behaviour close to a linear variation.
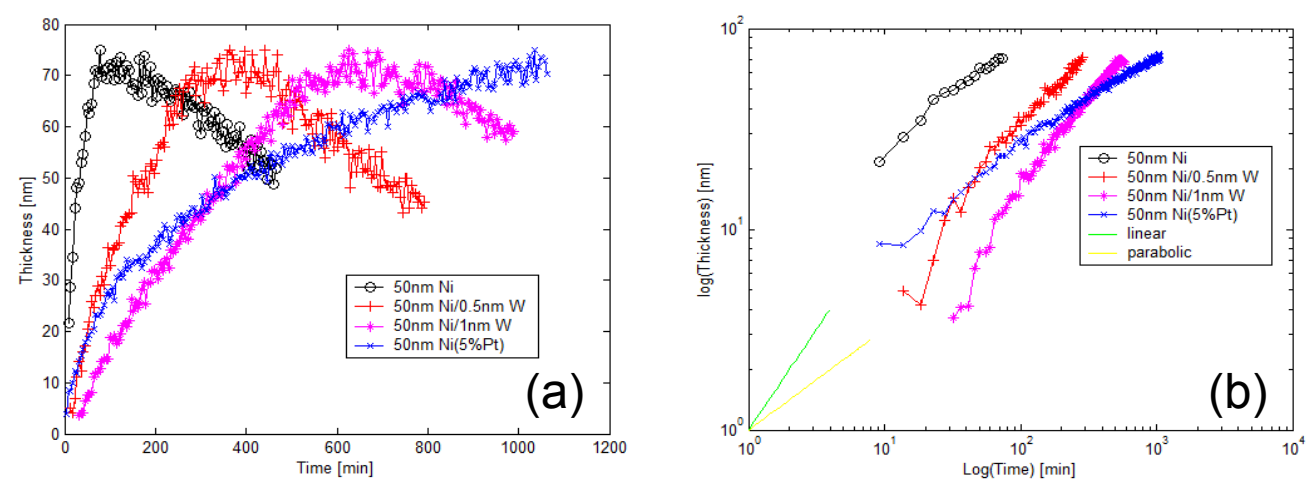
Fig. 13: Kinetics of $\delta-\mathrm{Ni}_{2} \mathrm{Si}$ growth for the different samples: (a) thickness as a function of time; (b) $\log$ (thickness) as a function of $\log$ (time): only the part corresponding to the growth of $\delta-\mathrm{Ni}_{2} \mathrm{Si}$ is shown and the linear (green line) and parabolic (yellow line) behavior are indicated at the origin to interpret the kinetics law. Note that the decrease in the $\delta-\mathrm{Ni}_{2} \mathrm{Si}$ thickness observed in (a) is due to the consumption of $\delta-\mathrm{Ni}_{2} \mathrm{Si}$ by NiSi. From Ref. [78].

In order to better understand the experimental results, two models for the kinetics of formation in the presence of a barrier have been developed [78]. It was considered that an intermetallic compound, $\delta=A_{p} B_{q}$, is growing by diffusion between two ends phases, $\alpha$ and $\gamma$, in the presence of a barrier, $\beta$, located between $\alpha$ and $\gamma$ (Fig. 14). The $\alpha$ phase is either a pure element or an alloy, $A_{1-x} C_{x}$. Moreover it was considered that (i) atom A is the main diffusing specie, (ii) the diffusion of $\mathrm{B}$ is negligible in all the phases, and (iii) the diffusion of $\mathrm{A}$ in the ends phases is negligible.

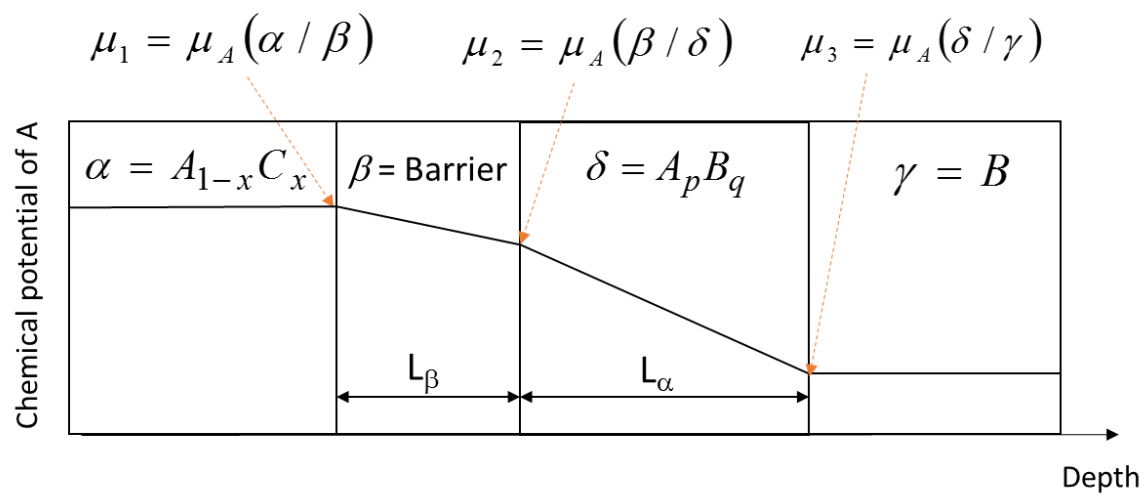

Fig. 14: Schematic of the growth of the phase in the presence of a barrier layer.

The barrier may have a fixed thickness and a fixed concentration. For examples, it can be the case if a layer is deposited between $\mathrm{A}$ and $\mathrm{B}$ or when a thin oxide layer is present at the $\mathrm{A} / \mathrm{B}$ interface. Under this conditions, it was shown that and are independent of time and Eq. 8 can be simplified to:

$$
\frac{d L^{\delta}}{d t}=\left(\frac{L^{\delta}}{D_{A}^{\delta}}+\frac{1}{\mathrm{~K}_{\beta}}\right)^{-1} \frac{\left(\mu_{1}-\mu_{3}\right)}{R T} .
$$

where $\mathrm{K}_{\beta}=\frac{c_{A}^{\beta} D_{A}^{\beta}}{c_{A}^{\delta} L^{\beta}}$.

$c_{A}^{\beta, \delta}, D_{A}^{\beta, \delta}$, and $L^{\beta, \delta}$ are, respectively, the concentration and the diffusivity of the diffusing species, and the thickness of either $\beta$ or $\delta . \mu_{1}$ and $\mu_{3}$ are the chemical potential at the $\alpha / \beta$ and $\delta / \gamma$ interfaces respectively. Eq. 16 is formally equivalent to the Deal and Groove law (Eq. 14). For isothermal heat treatment, Eq. 16 can be integrated to obtain a linear parabolic equation for the growth of the $\delta$ phase. The parameter $K_{\beta}$ depends mainly on two factors: the thickness of the barrier and its permeability defined as the product of the concentration and diffusion coefficient of $\mathrm{A}$ in the barrier, $P^{\beta}=c_{A}^{\beta} D_{A}^{\beta}$.

When the phase is formed from an alloy, $A_{1-x} C_{x}$, the $\mathrm{C}$ element can be not incorporated in the forming phase due to low diffusivity and/or low solubility: it will thus accumulate in the $\beta$ phase. As a first approximation, this case can be modelled as a barrier with a fixed concentration, $c_{C}^{\beta}$, i.e. $\beta=A_{1-x^{\beta}} C_{x^{\beta}}$, and a thickness that increases when the thickness of the $\delta$ phase increases. If the amount of $\mathrm{C}$ in the $\delta$ phase is negligible, the thickness of the barrier is then given by the conservation of matter: 


$$
L^{\beta}=\frac{c_{A}^{\delta} c_{C}^{\alpha}}{c_{A}^{\alpha} c_{C}^{\beta}-c_{A}^{\beta} c_{C}^{\alpha}} L^{\delta}
$$

The growth rate is then expressed as:

$$
\frac{d L^{\delta}}{d t}=\frac{D^{e f f}}{L^{\delta}} \frac{\left(\mu_{1}-\mu_{3}\right)}{R T} .
$$

Eq. 18 shows that in the case of barrier coming from an alloy, the growth inversely proportional to the thickness of the growing phase and is proportional to an effective coefficient :

$$
D^{\text {eff }}=\frac{1}{\frac{1}{D_{A}^{\delta}}+\frac{\chi}{D_{A}^{\beta}}}=\frac{D_{A}^{\delta}}{1+\chi \frac{D_{A}^{\delta}}{D_{A}^{\beta}}} \text { with } \chi=\frac{c_{C}^{\alpha}\left(c_{A}^{\delta}\right)^{2}}{c_{A}^{\beta}\left(c_{A}^{\alpha} c_{C}^{\beta}-c_{A}^{\beta} c_{C}^{\alpha}\right)}
$$

For isothermal heat treatment, the kinetics of formation will thus be parabolic.

In order to compare these models to experiments, the XRD in situ measurements have been fitted by Eq. 16 for the Ni film with or without W barrier and by Eq. 18 for the Ni(5 at.\% Pt) film. Fig. 15 shows that the simulation reproduce well the experimental variation of $\delta-\mathrm{Ni}_{2} \mathrm{Si}$ thickness for the different sample. In the fitting procedure, the kinetics for the Ni film without $\mathrm{W}$ barrier was first used to determine the diffusion coefficient of $\mathrm{Ni}$ in $\delta-\mathrm{Ni}_{2} \mathrm{Si}\left(D_{A}^{\delta}=0.04 \mathrm{~nm}^{2} / \mathrm{s}\right)$. The permeability of the barrier was then adjusted to fit the variation of $\delta-\mathrm{Ni}_{2} \mathrm{Si}$ thickness for the samples with $\mathrm{W}$ barrier (Eq. 16) and the NiPt sample (Eq. 18). Table 3 shows that the permeability are relatively close to each other for the three samples. The similar value for the two samples with $\mathrm{W}$ barrier validates that the linear term, $\mathrm{K}_{\beta}$, in Eq. 16 is indeed inversely proportional to the barrier thickness. It appears that the permeability (i.e. the "weakness") of the barrier is similar for W and Pt which is coherent with former results concerning the formation of $\mathrm{Ni}$ silicide from $\mathrm{Ni}(\mathrm{Pt})$ and $\mathrm{Ni}(\mathrm{W})$ alloy where the growth behaviour of this phase were similar. 
(a)

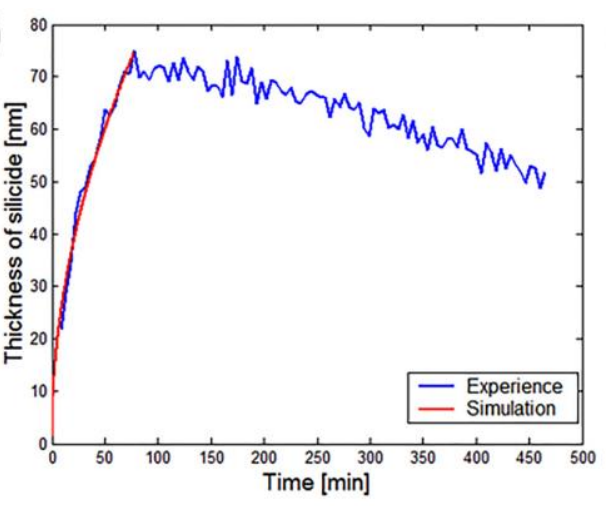

(c)

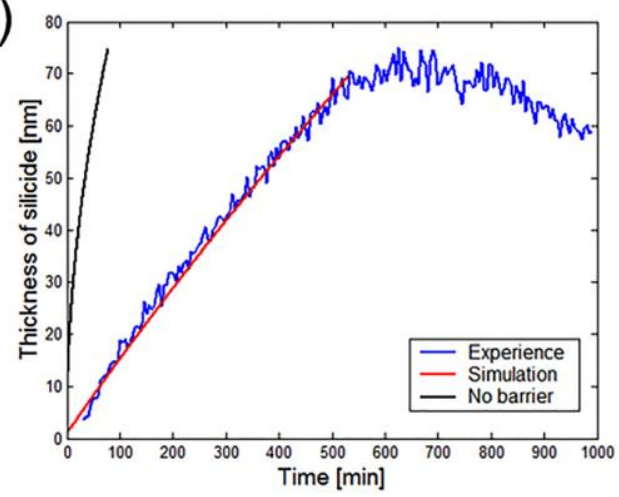

(b)

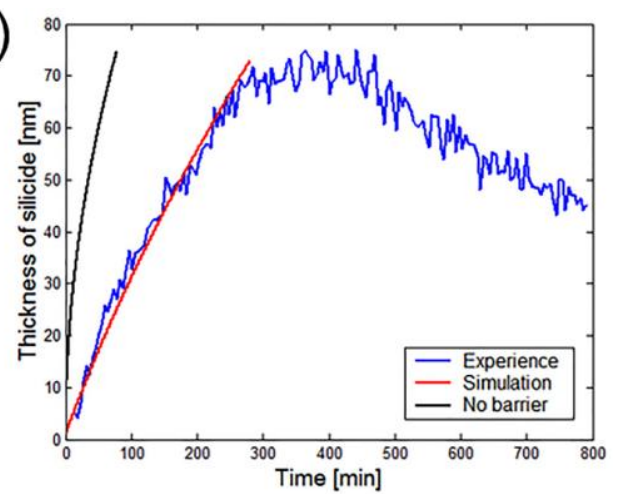

(d)

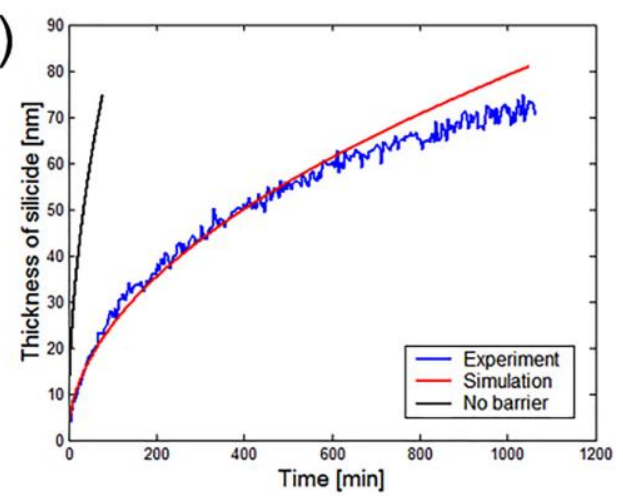

Fig. 15. Comparison between experience and simulation for (a) $50 \mathrm{~nm} \mathrm{Ni}$, (b) $50 \mathrm{~nm} \mathrm{Ni} / 0.5 \mathrm{~nm} \mathrm{~W}$, (c) $50 \mathrm{~nm}$ $\mathrm{Ni} / 1 \mathrm{~nm} \mathrm{~W}$, and (d) $\mathrm{Ni}(5 \%) \mathrm{Pt}$ films on $\mathrm{Si}(100)$. The simulation of the $\mathrm{Ni}$ film is also reproduced in (b), (c), and (d) to show the change in kinetics due to the barrier. From Ref. [78].

\begin{tabular}{|c|c|}
\hline Samples & $P_{A}^{\beta}=c_{A}^{\beta} D_{A}^{\beta}[\mathrm{at} / \mathrm{nm} . \mathrm{s}]$ \\
\hline $50 \mathrm{~nm} \mathrm{Ni} / 0.5 \mathrm{~nm} \mathrm{~W}$ & $1.310^{-2}$ \\
\hline $50 \mathrm{~nm} \mathrm{Ni} / 1 \mathrm{~nm} \mathrm{~W}$ & $1.010^{-2}$ \\
\hline $50 \mathrm{~nm} \mathrm{Ni} \% \mathrm{Pt}$ & $0.910^{-2}$ \\
\hline
\end{tabular}

Table 3: Permeability obtained from the fit of the experimental kinetics. The following parameters were taken for the fit: $\left(\mu_{1}-\mu_{3}\right) / R T=15$ and

$$
D_{A}^{\delta}=1 \mathrm{~nm}^{2} / \mathrm{s} .
$$

Fig. 15.d also shows that the simulation fits less well the experiment when the thickness of $\delta-\mathrm{Ni}_{2} \mathrm{Si}$ becomes large in the case of the $\mathrm{Ni}(\mathrm{Pt})$ film. This is certainly an indication of the limitation of the model for the alloy film. Indeed the assumption of a constant concentration and a constant diffusion coefficient is quite restrictive since the real situation may be more a gradient in the Pt concentration as indicated by APT measurement [51]

Note that Eq. 16 and 18 do not take into account the usual reaction barrier in the linear parabolic growth (Eq. 14) that account for the rearrangement of the atoms at the interfaces required for the growth of the compound layer [26]. This term can easily be included in these equations but should have a much lower impact on the kinetics that the barrier. The alloy element or the barrier element may also change the diffusion in the growing phase by segregating at the grain boundaries [52] as illustrated in Fig. 16. Indeed Pt was found to segregate at the grain boundary of $\delta-\mathrm{Ni}_{2} \mathrm{Si}$ [52] and could thus decrease the GB diffusion of Ni. Further work may be needed to separate the two effects. Grain growth in the barrier might also induce a change in the effective diffusion coefficient taking into account both inter and intra grain diffusion in the barrier. 


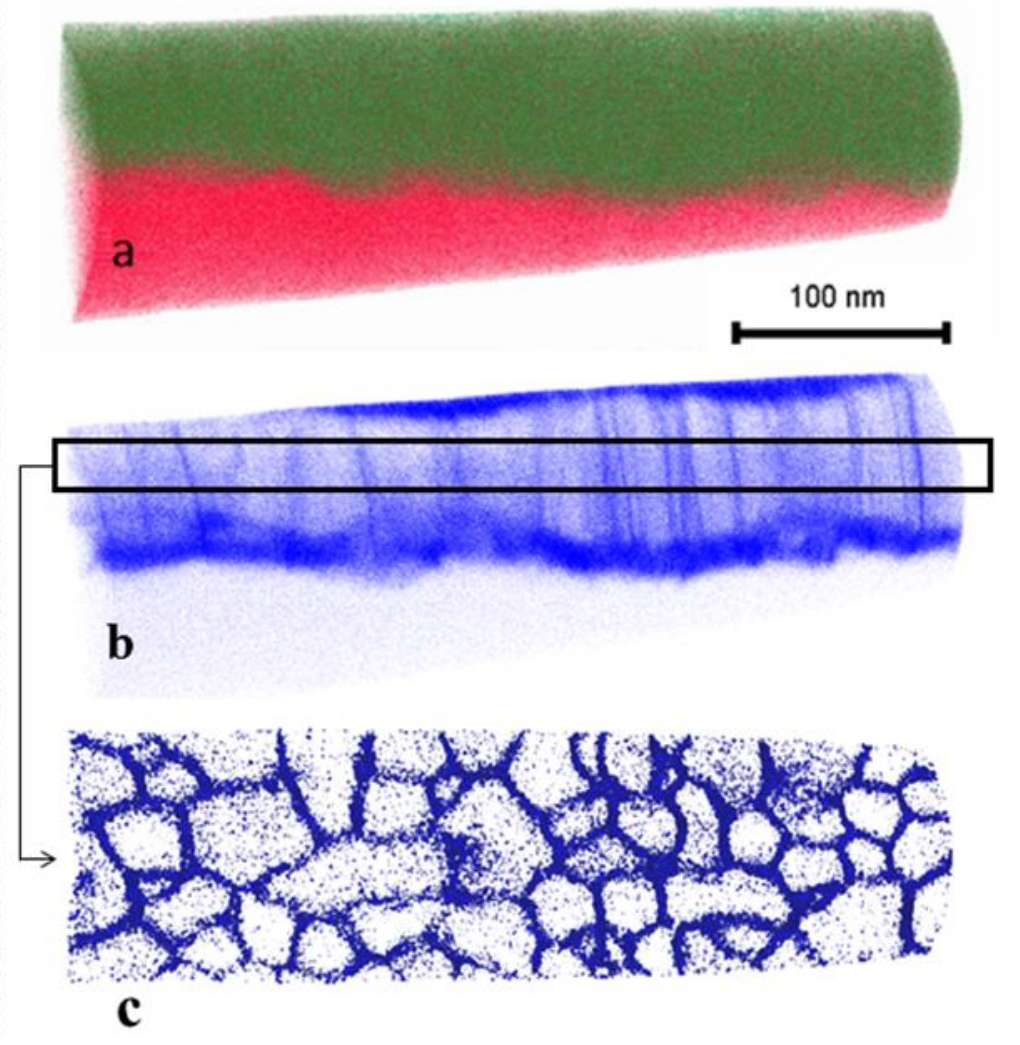

Fig. 16: APT reconstruction of a large $(120 \times 120 \times 400 \mathrm{~nm})$ analysis volume collected from the Ni silicide structure: (a) shows the $\mathrm{Si}$ (red dots) and $\mathrm{Ni}$ atoms (green dots); (b) shows the location of the $\mathrm{Pt}$ atoms (blue dots). Pt enrichment is observed at the top of the structure (corresponding to the unreacted $\mathrm{Ni}$ layer) and at the interface between silicide and silicon regions; (c) a 20 $\mathrm{nm}$ slice in depth through the $\delta-\mathrm{Ni}_{2} \mathrm{Si}$ region significant grain boundary enrichment of $\mathrm{Pt}(2$ at\% $\mathrm{Pt}$ isoconcentration surfaces shown) can be seen. In one single APT analysis it is now possible to capture many $(\sim 50)$ of these columnar features. From Ref. [79].

Whatsoever, even if the two models (Eq. 16 and 18) are simple, they allow to reproduce the experimental behaviour and in particular the difference in kinetics regime: linear-parabolic for a deposited barrier and parabolic for a barrier resulting from an alloy consumption. Furthermore the similarity between the permeability allows to validate the models. Further investigations are in progress to compare the permeability value for other alloy elements

These models (Eq. 16 and 18) are the basis for a simulation method to interpret the barrier effect and they match well with the dedicated model experiments that can be much more difficult to analyze for more complex systems. They should enable to better understand and to predict the barrier behavior both in fundamental studies and in some applications. They also allow to characterize the efficiency of a barrier by simple parameters such as the barrier permeability. Even if these parameters may depend on the barrier microstructure (for example grain size, grain structure, texture...), our first experiment shows that, for a given deposition process (sputtering in our case), these parameters could be materials constants.

\section{Conclusion}

Recent experimental results on the mechanisms of formation of silicide have been presented and compared to models and simulation in order to extract physical parameters that are relevant to reactive diffusion. These mechanisms include nucleation, lateral growth, diffusion/interface controlled growth, and the role of a diffusion barrier. Nucleation is critical not only when the driving force is low (high temperature nucleation of $\mathrm{NiSi}_{2}$ ) but also when two phases are in competition by having similar driving forces and similar kinetics of formation (case of the low temperature nucleation of $\delta$ $\mathrm{Ni}_{2} \mathrm{Si}$ and $\theta-\mathrm{Ni}_{2} \mathrm{Si}$ ). Lateral growth is an important step of the silicide formation. It has been evidenced by DSC and more recently by TEM. The comparison between results and models allows a better understanding of important parameters governing the lateral growth including interface energies, torque term, diffusion along interphases... The kinetics of thickening or normal growth was also simulated by a Deal and Grove law that allows to determine the interfacial rate of growth and the temperature/thickness relationship for the transition between the growth mainly controlled by diffusion or by the interface. This has important consequence for the formation of contact in 
microelectronics that should be mainly controlled by interface since small thickness and high temperature are used for the silicide process. The interface contribution is also of great importance for the sequential or simultaneous growth of silicides. The presence of a diffusion barrier can also induce a control by interface of the reactive diffusion if the barrier has a fixed thickness and composition. For a barrier built from an alloy film by the formation of the phase, the kinetics can be parabolic at least at the beginning of growth. The use of several techniques including in situ techniques (XRD, XRR, XPS, DSC) and high resolution techniques (APT and TEM) is essential for understanding these mechanisms as well as comparison with several models and simulation. Such combined analysis allows to gain understanding in the solid state reaction in thin films and to better control these reaction for making contacts in microelectronics devices or for other application.

\section{References:}

[1] J.P. Gambino, E.G. Colgan, Silicides and ohmic contacts, Mater. Chem. Phys. 52 (1998) 99-146. doi:10.1016/S0254-0584(98)80014-X.

[2] S.L. Zhang, M. Ostling, Metal silicides in CMOS technology: Past, present, and future trends, Crit. Rev. Solid State Mater. Sci. 28 (2003) 1-129. doi:10.1080/10408430390802431.

[3] C. Lavoie, F.M. d'Heurle, C. Detavernier, C. Cabral Jr., Towards implementation of a nickel silicide process for CMOS technologies, Microelectron. Eng. 70 (2003) 144-157. doi:10.1016/S0167-9317(03)00380-0.

[4] D. Mangelinck, J.Y. Dai, J.S. Pan, S.K. Lahiri, Enhancement of thermal stability of NiSi films on (100)Si and (111)Si by Pt addition, Appl. Phys. Lett. 75 (1999) 1736-1738. doi:10.1063/1.124803.

[5] P.S. Lee, K.L. Pey, D. Mangelinck, J. Ding, D.Z. Chi, L. Chan, New salicidation technology with Ni(Pt) alloy for MOSFETs, Ieee Electron Device Lett. 22 (2001) 568-570. doi:10.1109/55.974579.

[6] F.M. d'Heurle, P. Gas, Kinetics of formation of silicides: A review, J. Mater. Res. 1 (1986) 205-221. doi:10.1557/JMR.1986.0205.

[7] R. Tung, J. Poate, J. Bean, J. Gibson, D. Jacobson, Epitaxial Silicides, Thin Solid Films. 93 (1982) 77-90. doi:10.1016/0040-6090(82)90093-1.

[8] M.-A. Nicolet, S.S. Lau, Chapter 6 - Formation and Characterization of Transition-Metal Silicides, in: N.G. Einspruch, G.B. Larrabee (Eds.), VLSI Electron. Microstruct. Sci., Elsevier, 1983: pp. 329-464. doi:10.1016/B978-0-12-234106-9.50011-8.

[9] F.M. d'Heurle, O. Thomas, Stresses during Silicide Formation: A Review, Defect Diffus. Forum. 129-130 (1996) 137-150. doi:10.4028/www.scientific.net/DDF.129-130.137.

[10] F. Nava, K.N. Tu, O. Thomas, J.P. Senateur, R. Madar, A. Borghesi, G. Guizzetti, U. Gottlieb, O. Laborde, O. Bisi, Electrical and optical properties of silicide single crystals and thin films, Mater. Sci. Rep. 9 (1993) 141-200. doi:10.1016/0920-2307(93)90007-2.

[11] F.M. d'Heurle, Nucleation of a new phase from the interaction of two adjacent phases: Some silicides, J. Mater. Res. 3 (1988) 167-195. doi:10.1557/JMR.1988.0167.

[12] K. Coffey, L. Clevenger, K. Barmak, D. Rudman, C. Thompson, Experimental-Evidence for Nucleation During Thin-Film Reactions, Appl. Phys. Lett. 55 (1989) 852-854. doi:10.1063/1.102447.

[13] P. Gergaud, O. Thomas, B. Chenevier, Stresses arising from a solid state reaction between palladium films and $\mathrm{Si}(001)$ investigated by in situ combined x-ray diffraction and curvature measurements, J. Appl. Phys. 94 (2003) 1584-1591. doi:10.1063/1.1590059.

[14] C. Rivero, P. Gergaud, M. Gailhanou, O. Thomas, B. Froment, H. Jaouen, V. Carron, Combined synchrotron Xray diffraction and wafer curvature measurements during Ni-Si reactive film formation, Appl. Phys. Lett. 87 (2005) 041904. doi:10.1063/1.1999021.

[15] D. Mangelinck, K. Hoummada, Effect of stress on the transformation of Ni2Si into NiSi, Appl. Phys. Lett. 92 (2008) 254101. doi:10.1063/1.2949751.

[16] C. Detavernier, A.S. Ozcan, J. Jordan-Sweet, E.A. Stach, J. Tersoff, F.M. Ross, C. Lavoie, An off-normal fibrelike texture in thin films on single-crystal substrates, Nature. 426 (2003) 641-645. doi:10.1038/nature02198.

[17] D. Mangelinck, K. Hoummada, I. Blum, Kinetics of a transient silicide during the reaction of Ni thin film with (100)Si, Appl. Phys. Lett. 95 (2009) 181902. doi:10.1063/1.3257732.

[18] Z. Zhang, S.-L. Zhang, B. Yang, Y. Zhu, S.M. Rossnagel, S. Gaudet, A.J. Kellock, J. Jordan-Sweet, C. Lavoie, Morphological stability and specific resistivity of sub-10 nm silicide films of Ni1-xPtx on Si substrate, Appl. Phys. Lett. 96 (2010) 071915. doi:10.1063/1.3323097.

[19] J. Lu, J. Luo, S.-L. Zhang, M. Ostling, L. Hultman, On Epitaxy of Ultrathin Ni1-xPtx Silicide Films on Si(001), Electrochem. Solid State Lett. 13 (2010) H360-H362. doi:10.1149/1.3473723.

[20] K. De Keyser, C. Van Bockstael, R.L. Van Meirhaeghe, C. Detavernier, E. Verleysen, H. Bender, W. Vandervorst, J. Jordan-Sweet, C. Lavoie, Phase formation and thermal stability of ultrathin nickel-silicides on Si(100), Appl. Phys. Lett. 96 (2010) 173503. doi:10.1063/1.3384997. 
[21] P. Gas, F.M. D’Heurle, Diffusion in Silicide, in: Diffus. Semicond. Non-Met. Solids, Ed. D.L. Beke, Springer Verlag, Berlin, 1998.

[22] T. Barge, Formation de siliciures par réaction métal-silicium: role de la diffusion, (1993).

[23] T. Barge, P. Gas, F.M. d'Heurle, Analysis of the diffusion controlled growth of cobalt silicides in bulk and thin film couples, J. Mater. Res. 10 (1995) 1134-1145. doi:10.1557/JMR.1995.1134.

[24] W.K. Chu, J.W. Mayer, M.-A. Nicolet, Backscattering Spectrometry, Academic Press, New York, 1978.

[25] S.-L. Zhang, F.M. d'Heurle, Precisions on reaction monitoring from in-situ resistance measurements: relations between such measurements and actual reaction kinetics, Thin Solid Films. 279 (1996) 248-252. doi:10.1016/0040-6090(95)08192-5.

[26] C. Michaelsen, K. Barmak, T.P. Weihs, Investigating the thermodynamics and kinetics of thin film reactions by differential scanning calorimetry, J. Phys. -Appl. Phys. 30 (1997) 3167-3186. doi:10.1088/0022-3727/30/23/001.

[27] F. Nemouchi, D. Mangelinck, C. Bergman, P. Gas, U. Smith, Differential scanning calorimetry analysis of the linear parabolic growth of nanometric Ni silicide thin films on a Si substrate, Appl. Phys. Lett. 86 (2005) 041903. doi:10.1063/1.1852727.

[28] M. Putero, L. Ehouarne, E. Ziegler, D. Mangelinck, First silicide formed by reaction of Ni(13\%Pt) films with $\operatorname{Si}\left(\begin{array}{lll}1 & 0 & 0\end{array}\right)$ : Nature and kinetics by in-situ X-ray reflectivity and diffraction, Scr. Mater. 63 (2010) 24-27. doi:10.1016/j.scriptamat.2010.02.040.

[29] H.E. Kissinger, Reaction Kinetics in Differential Thermal Analysis, Anal. Chem. 29 (1957) 1702.

[30] S.-L. Zhang, F.M. d'Heurle, Kinetic studies of intermetallic compound formation by resistance measurements, Thin Solid Films. 256 (1995) 155-164. doi:10.1016/0040-6090(94)06288-9.

[31] H. Bakker, Self Diffusion in Homogeneous Binary Alloys and Intermediate Phases., Springer, Berlin, 1990.

[32] H. Mehrer, Diffusion in Solids: Fundamentals, Methods, Materials, Diffusion-Controlled Processes, Springer Science \& Business Media, 2007.

[33] P. Gas, Diffusion mechanism in bulk silicides: Relation with thin film behaviour (case of Ni2Si formation), Appl. Surf. Sci. 38 (1989) 178-184. doi:10.1016/0169-4332(89)90534-5.

[34] P. Gas, F.M. d'Heurle, Formation of silicide thin films by solid state reaction, Appl. Surf. Sci. 73 (1993) 153161. doi:10.1016/0169-4332(93)90160-D.

[35] D.S. Wen, P.L. Smith, C.M. Osburn, G.A. Rozgonyi, Defect annihilation in shallow p+ junctions using titanium silicide, Appl. Phys. Lett. 51 (1987) 1182. doi:10.1063/1.98726.

[36] N. Stolwijk, H. Bracht, H.-G. Hettwer, W. Lerch, H. Mehrer, A. Rucki, W. Jäger, Defect Injection and Diffusion in Semiconductors, Mater. Sci. Forum. 155-156 (1994) 475-492. doi:10.4028/www.scientific.net/MSF.155156.475 .

[37] W.K. Chu, S.S. Lau, J.W. Mayer, H. Müller, K.N. Tu, Implanted noble gas atoms as diffusion markers in silicide formation, Thin Solid Films. 25 (1975) 393-402. doi:10.1016/0040-6090(75)90057-7.

[38] J.O. Olowolafe, M.-A. Nicolet, J.W. Mayer, Influence of the nature of the Si substrate on nickel silicide formed from thin Ni films, Thin Solid Films. 38 (1976) 143-150. doi:10.1016/0040-6090(76)90221-2.

[39] T.B. Massalski, H. Okamoto, ASM International, Binary alloy phase diagrams, ASM International, Materials Park, Ohio, 1990.

[40] L. Clevenger, C. Thompson, R. Cammarata, K. Tu, Reaction-Kinetics of Nickel Silicon Multilayer Films, Appl. Phys. Lett. 52 (1988) 795-797. doi:10.1063/1.99644.

[41] L. Clevenger, C. Thompson, Nucleation-Limited Phase Selection During Reactions in Nickel Amorphous-Silicon Multilayer Thin-Films, J. Appl. Phys. 67 (1990) 1325-1333. doi:10.1063/1.345685.

[42] C. Lavoie, C. Coia, F.M. d'Heurle, C. Detavernier, C. Cabral, P. Desjardins, A.J. Kellock, Reactive diffusion in the Ni-Si system: phase sequence and formation of metal-rich phases, in: M. Danielewski, R. Filipek, R. Kozubs, W. Kucza, P. Zieba, Z. Zurek (Eds.), Diffus. Mater. Dimat 2004 Pts 1 2, 2005: pp. 825-836.

[43] S. Gaudet, C. Coia, P. Desjardins, C. Lavoie, Metastable phase formation during the reaction of Ni films with $\mathrm{Si}(001)$ : The role of texture inheritance, J. Appl. Phys. 107 (2010) 093515. doi:10.1063/1.3327451.

[44] C. Coia, Metastable compound formation during thin-film solid state reaction in the Ni-Si system: microstructure and growth kinetics, (2008).

[45] P.J. Grunthaner, Metal/silicon interface formation: The Ni/Si and Pd/Si systems, J. Vac. Sci. Technol. 19 (1981) 649. doi:10.1116/1.571079.

[46] F. d'Heurle, C.S. Petersson, J.E.E. Baglin, S.J. La Placa, C.Y. Wong, Formation of thin films of NiSi: Metastable structure, diffusion mechanisms in intermetallic compounds, J. Appl. Phys. 55 (1984) 4208. doi:10.1063/1.333021.

[47] C. Detavernier, C. Lavoie, Influence of Pt addition on the texture of NiSi on Si(001), Appl. Phys. Lett. 84 (2004) 3549. doi:10.1063/1.1719276.

[48] F. Panciera, D. Mangelinck, K. Hoummada, M. Texier, M. Bertoglio, A. De Luca, M. Gregoire, M. Juhel, Direct

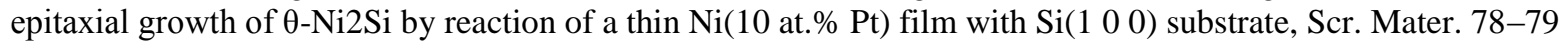
(2014) 9-12. doi:10.1016/j.scriptamat.2014.01.010.

[49] F. Panciera, La sonde atomique tomographique : applications aux dispositifs CMOS avancés sub-45nm, (2012).

[50] M. El Kousseifi, K. Hoummada, M. Bertoglio, D. Mangelinck, Selection of the first Ni silicide phase by controlling the Pt incorporation in the intermixed layer, Acta Mater. 106 (2016) 193-198. doi:10.1016/j.actamat.2016.01.004. 
[51] W.H. Wang, H.Y. Bai, Y. Zhang, W.K. Wang, Phase selection in interfacial reaction of Ni/amorphous Si multilayers, J. Appl. Phys. 73 (1993) 4313-4318. doi:10.1063/1.352814.

[52] F.M. d'Heurle, P. Gas, Kinetics of formation of silicides: A review, J. Mater. Res. 1 (1986) $205-221$. doi:10.1557/JMR.1986.0205.

[53] K. Hoummada, D. Mangelinck, A. Portavoce, Kinetic of Formation of Ni and Pd Silicides: Determination of Interfacial Mobility and Interdiffusion Coefficient by \&lt;i\&gt;In Situ\&lt;/i\&gt; Techniques, Solid State Phenom. 172-174 (2011) 640-645. doi:10.4028/www.scientific.net/SSP.172-174.640.

[54] K. Hoummada, A. Portavoce, C. Perrin-Pellegrino, D. Mangelinck, C. Bergman, Differential scanning calorimetry measurements of kinetic factors involved in salicide process, Appl. Phys. Lett. 92 (2008) 133109. doi:10.1063/1.2905293.

[55] K. Coffey, K. Barmak, D. Rudman, S. Foner, Thin-Film Reaction-Kinetics of Niobium Aluminum Multilayers, J. Appl. Phys. 72 (1992) 1341-1349. doi:10.1063/1.351744.

[56] G. Lucadamo, K. Barmak, S. Hyun, C. Cabral Jr., C. Lavoie, Evidence of a two-stage reaction mechanism in sputter deposited $\mathrm{Nb} / \mathrm{Al}$ multilayer thin-films studied by in situ synchrotron X-ray diffraction, Mater. Lett. 39 (1999) 268-273. doi:10.1016/S0167-577X(99)00017-8.

[57] C. Bergman, J.L. Joulaud, M. Capitan, G. Clugnet, P. Gas, In situ real-time analysis of the formation of a quasicrystalline phase in Al-Co multilayers by solid-state reaction, J. Non-Cryst. Solids. 287 (2001) 193-196. doi:10.1016/S0022-3093(01)00558-0.

[58] R. Delattre, O. Thomas, C. Perrin-Pellegrino, C. Rivero, R. Simola, First stage of CoSi2 formation during a solidstate reaction, J. Appl. Phys. 116 (2014) 245301. doi:10.1063/1.4904852.

[59] V. Vovk, G. Schmitz, R. Kirchheim, Nucleation of product phase in reactive diffusion of Al/Co, Phys. Rev. B. 69 (2004). doi:10.1103/PhysRevB.69.104102.

[60] K. Hoummada, E. Cadel, D. Mangelinck, C. Perrin-Pellegrino, D. Blavette, B. Deconihout, First stages of the formation of Ni silicide by atom probe tomography, Appl. Phys. Lett. 89 (2006) 181905. doi:10.1063/1.2370501.

[61] L. Klinger, Y. Bréchet, G. Purdy, On the kinetics of interface-diffusion-controlled peritectoid reactions, Acta Mater. 46 (1998) 2617-2621. doi:10.1016/S1359-6454(97)00471-0.

[62] G. Lucenko, A. Gusak, A model of the growth of intermediate phase islands in multilayers, Microelectron. Eng. 70 (2003) 529-532. doi:10.1016/S0167-9317(03)00432-5.

[63] M. Pasichnyy, A. Gusak, Model of Lateral Growth Stage during Reactive Phase Formation, Defect Diffus. Forum. 277 (2008) 47-52. doi:10.4028/www.scientific.net/DDF.277.47.

[64] F.R. de Boer, A.R. Niessen, A.R. Miedema, W.C.M. Mattens, R. Boom, Cohesion in Metals, Elsevier Science Ltd, Amsterdam, 1988.

[65] E. Ma, L. Clevenger, C. Thompson, Nucleation of an Intermetallic at Thin-Film Interfaces - Vsi2 Contrasted with Al3ni, J. Mater. Res. 7 (1992) 1350-1355. doi:10.1557/JMR.1992.1350.

[66] J.W. Christian, The Theory of Transformation Rates in Metals and Alloys, Part I, Pergamon, Oxford, 1975.

[67] M. El Kousseifi, K. Hoummada, T. Epicier, D. Mangelinck, Direct observation of NiSi lateral growth at the epitaxial $\theta$-Ni2Si/Si(1 0 0) interface, Acta Mater. 99 (2015) 1-6. doi:10.1016/j.actamat.2015.07.062.

[68] D. Mangelinck, M. El Kousseifi, K. Hoummada, F. Panciera, T. Epicier, Lateral growth of NiSi at the $\theta$ Ni2Si/Si(100) interface: Experiments and modelling, Microelectron. Eng. 199 (2018) 45-51. doi:10.1016/j.mee.2018.07.014.

[69] S.V. Divinski, F. Hisker, A. Bartels, C. Herzig, Interphase boundary diffusion of 44Ti in two-phase TiAl with lamellar $\alpha 2 / \gamma$ structure, Scr. Mater. 45 (2001) 161-167. doi:10.1016/S1359-6462(01)01006-5.

[70] C. Herring, Surface tension as a motivation for sintering, in: Phys. Powder Metall., McGraw-Hill Book Co., W.E. Kingston, New York, 1951: p. 143.

[71] B.L. Adams, S. Ta'Asan, D. Kinderlehrer, I. Livshits, D.E. Mason, C.-T. Wu, W.W. Mullins, G.S. Rohrer, A.D. Rollett, D.M. Saylor, Extracting Grain Boundary and Surface Energy from Measurement of Triple Junction Geometry, Interface Sci. 7 (1999) 321-337. doi:10.1023/A:1008733728830.

[72] H.I. Aaronson, M. Enomoto, J.K. Lee, Mechanisms of Diffusional Phase Transformations in Metals and Alloys, CRC Press, 2016.

[73] F. Nemouchi, Réactivité de films nanometriques de nickel sur substrats silicium-germanium, (2005).

[74] B.E. Deal, A.S. Grove, General Relationship for the Thermal Oxidation of Silicon, J. Appl. Phys. 36 (1965) 3770. doi:10.1063/1.1713945.

[75] F. Nemouchi, D. Mangelinck, C. Bergman, G. Clugnet, P. Gas, J.L. Lábár, Simultaneous growth of Ni5Ge3 and NiGe by reaction of Ni film with Ge, Appl. Phys. Lett. 89 (2006) 131920. doi:10.1063/1.2358189.

[76] F. Nemouchi, D. Mangelinck, J.L. Lábár, M. Putero, C. Bergman, P. Gas, A comparative study of nickel silicides and nickel germanides: Phase formation and kinetics, Microelectron. Eng. 83 (2006) 2101-2106. doi:10.1016/j.mee.2006.09.014.

[77] D. Mangelinck, Chapter 9 - The Growth of Silicides and Germanides, in: Handb. Solid State Diffus. Vol. 2 , Elsevier, 2017: pp. 379-446. doi:10.1016/B978-0-12-804548-0.00009-8.

[78] D. Mangelinck, T. Luo, C. Girardeaux, Reactive diffusion in the presence of a diffusion barrier: Experiment and model, J. Appl. Phys. 123 (2018) 185301. doi:10.1063/1.5023578. 
[79] D. Mangelinck, K. Hoummada, A. Portavoce, C. Perrin, R. Daineche, M. Descoins, D.J. Larson, P.H. Clifton, Three-dimensional composition mapping of NiSi phase distribution and Pt diffusion via grain boundaries in Ni2Si, Scr. Mater. 62 (2010) 568-571. doi:10.1016/j.scriptamat.2009.12.044. 